\title{
12 Motivation und Volition im Handlungsverlauf
}

\author{
A. Achtziger, P. M. Gollwitzer
}

12.1 Besonderheiten der Handlungsperspektive -309

\subsection{Das Rubikon-Modell der Handlungs-} phasen -310

12.2.1 Handlungsphasen -310

12.2.2 Motivationale vs. volitionale Handlungsphasen - 313

12.3 Handlungsphasen und Bewusstseinslagen oder die Frage "Wie bringt man psychologische Prozesse in ein idealtypisches, strukturelles Modell?» - 314

12.4 Unterschiedliche Effekte der Bewusstseinslagen des Abwägens und Planens - 316

12.4.1 Kognitives Tuning auf aufgabenkongruente Informationen - 316

12.4.2 Verarbeitung relevanter und irrelevanter Informationen -317

12.4.3 Verzerrte Verarbeitung relevanter Informationen hinsichtlich der Realisierbarkeit und Wünschbarkeit eines Ziels - 318

12.4.4 Bewusstseinslagen und Selbstbewertung -319

12.4.5 Moderatoreffekte in der abwägenden und planenden Bewusstseinslage $\quad-320$

12.4.6 Bewusstseinslagen und Zielrealisierung -321

12.4.7 Abschließende Diskussion: Bewusstseinslagen und die Selbstregulation des Zielstrebens $\quad-321$
12.5 Unterschiedliche Arten von Handlungsintentionen: Zielintentionen (Absichten) und Durchführungsintentionen (Vorsätze) -322

12.5.1 Wie funktionieren Vorsätze? - 323

12.5.2 Vorsätze und die Initiierung erwünschter Zielhandlungen -326

12.6 Vorsätze und die Kontrolle unerwünschten Verhaltens - 327

12.6.1 Suppressionsvorsätze -328

12.6.2 Blockieren nachteiliger Selbstzustände durch Planen der gewollten Handlung -329

12.6.3 Blockieren nachteiliger kontextueller Einflüsse durch Planen der gewollten Handlung -330

12.7 Potenzielle Kosten der Handlungskontrolle durch Vorsätze - 332

12.7.1 Rigidität und vorsatzgesteuertes Handeln - 332

12.7.2 Vorsätze und Selbstregulierungskapazität - 333

12.7.3 Vorsätze und Rebound-Effekte - 333

12.8 Diskussion und Ausblick - 334

12.8.1 Fassen von Vorsätzen als narrensichere Selbstregulationsstrategie? - 334

12.8.2 Kognitive und Neuronale Basis - 334

\subsection{Besonderheiten der Handlungs- perspektive}

Für Kurt Lewin (vgl. Lewin, Dembo, Festinger \& Sears, 1944) bestand nie ein Zweifel daran, dass Phänomene des Motiviertseins nur aus einer Handlungsperspektive heraus adäquat verstanden und analysiert werden können. Dies sei deshalb so, weil Prozesse des Zielsetzens (»goal setting«) und der Zielrealisierung (»goal striving «) jeweils anderen psychologischen Prinzipien unterliegen. Diese Einsicht blieb lange Zeit unberücksichtigt, wahrscheinlich aus dem einfachen Grund, weil die Analyse des Zielsetzens anhand von Erwartungs-Wert-Modellen sehr erfolgreich war (Festinger, 1942; Atkinson, 1957) und so die ganze Aufmerksamkeit der Motivationspsychologie band. Erst mit dem Erwachen der Zielpsychologie (beginnend mit Klingers »current concerns «, 1977, und Wicklund und Gollwitzers »self-definitional goals«, 1982) und der Psychologie der Handlungskontrolle (basierend auf Kuhls Analyse der Lage- vs. Handlungsorientierung, 1983; - detaillierte Ausführungen in Kap. 13) wurde den Prozessen und den mehr oder weniger erfolgreichen Strategien der Zielrealisierung die Aufmerksamkeit zu teil, die ihnen Kurt Lewin bereits in den 40er-Jahren zugedacht hatte (Oettingen \& Gollwitzer, 2001). Menschliches Verhalten aus einer Handlungsperspektive zu betrachten, bedeutet im Gegensatz zu einer behavioristischen Betrachtungsweise auch, die Analyse des Verhaltens nicht nur auf das Reagieren und das Ausführen gelernter Gewohnheiten zu begrenzen. Der Begriff »Handlung« soll dem reinen Ausführen gelernter Gewohnheiten oder automatischer Reaktionen entgegengesetzt werden, um selektiv menschliches Verhalten zu bezeichnen, das mit "Sinn« in Verbindung gebracht werden kann. Nach Max Weber (1921) ist "Handeln« alles menschliche Verhalten, mit dem der Handelnde einen "Sinn" verbindet. Für Außenstehende gilt als Kriterium zur Feststellung, ob eine andere Person »gehandelt« hat, die Antwort auf die Frage, 
ob sie den »Sinn« oder die »Gründe« dieser Person zur Ausübung dieses Verhaltens nachvollziehen kann.

\section{$>$ Definition \\ Als Handlung gelten in diesem Sinne alle Aktivitäten, denen eine »Zielvorstellung« zugrunde liegt.}

Die motivationspsychologische Handlungspsychologie untersucht v. a. Fragen der Handlungssteuerung. Das ist insofern wichtig, als in der handlungspsychologischen Forschung häufig festgestellt wurde, dass eine starke Motivation, ein bestimmtes Handlungsergebnis zu erzielen oder ein bestimmtes Verhalten zu zeigen, im Normalfall nicht dafür ausreicht, dieses Verhalten auch wirklich durchzuführen, um damit ein Ziel zu realisieren (Gollwitzer \& Bargh, 1996; Heckhausen, 1989; Kuhl, 1983). Vielmehr erfordert ein tatsächlicher Handlungserfolg häufig den geschickten Einsatz verschiedener Handlungskontrollstrategien (z. B. das Fassen von Wenn-Dann-Plänen, die Wiederaufnahme unterbrochener Handlungen, eine Anstrengungssteigerung angesichts von Schwierigkeiten; vgl. Gollwitzer \& Moskowitz, 1996; A Abschn. 12.5-12.7).

\subsection{Das Rubikon-Modell der Handlungsphasen}

In diesem Abschnitt soll der Handlungsverlauf beschrieben werden. Dieser wird im Rubikon-Modell der Handlungsphasen als ein zeitlicher und somit horizontaler Pfad verstanden, der mit den Wünschen einer Person beginnt und mit der Bewertung des jeweils erreichten Handlungszieles endet (Gollwitzer, 1990; Heckhausen, 1987a; 1989; Heckhausen \& Gollwitzer, 1987). Das RubikonModell versucht Antworten auf die folgenden Fragen zu geben:

- Wie wählt ein Handelnder seine Ziele aus?

- Wie plant er deren Realisierung?

- Wie führt er diese Pläne durch?

- Wie bewertet er seine Bemühungen um die Erreichung seines Handlungsziels?

(2) Die entscheidende Innovation des Rubikon-Modells liegt in der Identifikation der diskreten Wechsel zwischen motivationalen und volitionalen Handlungsphasen, die einem funktionskongruenten Wechsel zwischen Bewusstseinslagen, die dem Abwägen von Zielen und ihrer Realisierung dienlich sind. Die drei wichtigsten Phasenübergänge betreffen den Wechsel von der Motivationsphase vor einer Handlungsentscheidung zur Volitionsphase nach einer Handlungsentscheidung, den Übergang zur eigentlichen Handlungsinitiierung und schließlich den Übergang von der Handlungsphase zurück in die motivationale (postaktionale) Bewertungsphase.

\subsubsection{Handlungsphasen}

Für Heckhausen war der Ausgangspunkt für die Entwicklung des Rubikon-Modells der Handlungsphasen die Notwendigkeit, die zwei Grundprobleme der Motivationspsychologie, nämlich die Wahl von Handlungszielen einerseits und die Realisierung dieser Ziele andererseits (Lewin, 1926b), zugleich zu unterscheiden und in ein gemeinsames Rahmenmodell zu integrieren (Heckhausen, 1987a, 1989; Heckhausen \& Gollwitzer, 1987). Anders ausgedrückt handelt es sich hier um den Übergang vom Wünschen zum Wählen in der Zielauswahl und vom Wählen zum Wollen in der handelnden Zielverfolgung (Heckhausen, 1987b). Dabei soll die Verschiedenheit der beiden Problemstellungen deutlich zum Ausdruck kommen und jeder Versuchung widerstanden werden, sie zu vermengen oder als ein und dasselbe aufzufassen. Denn gerade dies hatte in der Geschichte der Motivationspsychologie zu Verwirrung und letztlich zur jahrzehntelangen Vernachlässigung volitionaler Phänomene geführt (Heckhausen, 1987c, 1989; Kuhl, 1983, Gollwitzer, 1990, 1991). Andererseits sind die beiden Prozesse Zielwahl und Zielrealisierung jedoch auch funktional verknüpft und sollten daher nicht als isolierte, voneinander unabhängige Einzelphänomene konzipiert werden. Das Rubikon-Modell löst diesen Anspruch ein, indem es die Entstehung einer Motivationstendenz vom Wünschen, zum Wählen und Wollen bis hin zu ihrer Deaktivierung über die Zeit hinweg verfolgt. Es versucht das Entstehen, Heranreifen und Vergehen von Motivation zu beschreiben. Hierbei unterteilt es den Handlungsverlauf in vier natürliche, chronologisch aufeinander folgende und durch diskrete Übergänge voneinander abgesetzte Phasen. Diese unterscheiden sich hinsichtlich der Aufgaben, die sich einem Handelnden jeweils dann stellen, wenn er eine bestimmte Phase erfolgreich abschließen will und begründen so ein strukturfunktionales Modell aufeinander folgender Handlungsphasen.

Nach dem Rubikon-Modell erstreckt sich der Handlungsverlauf von der Phase des Abwägens verschiedener Wünsche und Handlungsoptionen und deren jeweiliger positiver und negativer Konsequenzen (prädezisionale Handlungsphase) über die Phase des Planens konkreter Strategien, mit denen eine Person versucht, das am Ende der prädezisionalen Phase etablierte Ziel zu realisieren (präaktionale/postdezisionale Handlungsphase), bis hin zur einer Phase der Durchführung dieser Strategien (aktionale Handlungsphase) und einer Phase der Bewertung des sich daraus ergebenden Handlungsergebnisses (postaktionale Handlungsphase; - Abb. 12.1; auch Kap. 1, - Abb. 1.3).

(D) Die 4 Phasen des Rubikon-Modells unterscheiden sich hinsichtlich der Aufgaben, die sich einem Handelnden stellen, wenn er eine bestimmte Phase erfolgreich abschließen will. Der Geschehensablauf des Motiviertseins wird dabei in »natürliche« und somit eigenständig erscheinende Phasen aufgeteilt, wobei das Rubikon-Modell beansprucht, sowohl das Setzen von Zielen, als auch das Streben nach und die Realisierung von gesetzten Zielen zu erklären.

\section{Die prädezisionale Handlungsphase}

Die 1. Phase (prädezisionale Handlungsphase) ist dadurch gekennzeichnet, dass ein Handelnder sich zunächst darüber klar werden muss, welchen seiner Wünsche und Anliegen er überhaupt in die Tat umsetzen möchte. Die Motive einer Person werden hierbei als mehr oder weniger stark sprudelnde Quellen der Wunschproduktion verstanden. So wird beispielsweise von einer Person mit einem ausgeprägten Leistungsmotiv und einem niedrigen Affiliationsmotiv ( $>$ Kap. 7) erwartet, dass sie viele leistungsbezogene, aber nur wenige affiliationsbezogene Wünsche erlebt. Da die Bedürfnisse und Motive der Menschen gewöhnlich mehr Wünsche und Anliegen produzieren als realisiert werden 
- Abb. 12.1. Das Rubikon-Modell der Handlungsphasen (Heckhausen \& Gollwitzer, 1987)

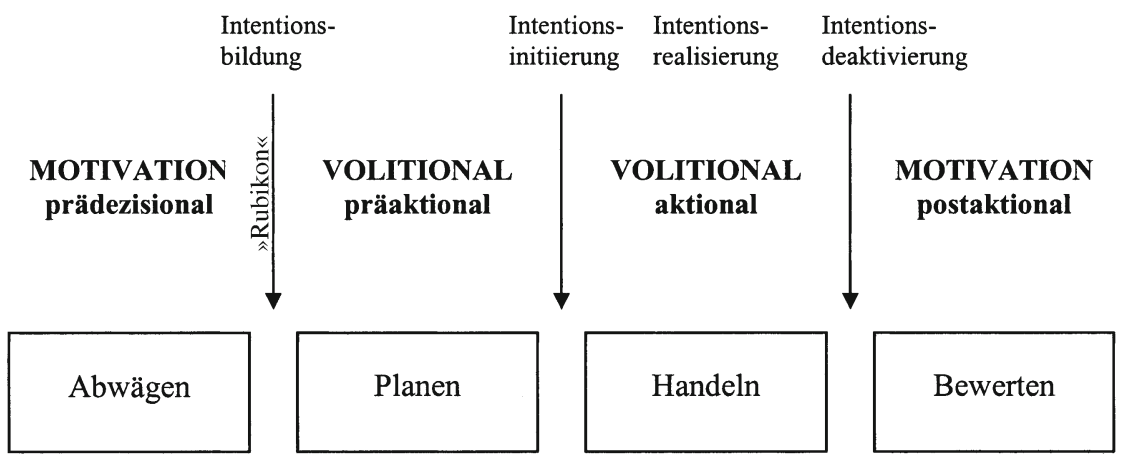

können, ist ein Handelnder dazu gezwungen, sich zwischen diesen Wünschen und Anliegen zu entscheiden und einige davon in verbindliche Ziele umzusetzen. Zu diesem Zweck wägt er die Wünschbarkeit und Realisierbarkeit der verschiedenen Wünsche und Anliegen gegeneinander ab. In dieser Phase geht es also darum, gemäß den Kriterien der Realisierbarkeit (d. h. der Erwartung, dass das eigene Handeln zum Erfolg führt) und der Wünschbarkeit (d. h. dem Wert des erwarteten Handlungsergebnisses) zu entscheiden, welchen seiner Wünsche man wirklich in die Tat umsetzen will. Bei der Analyse der Realisierbarkeit sieht man sich vor Fragen gestellt, wie z. B.:

- Kann man die erwünschten Ereignisse durch eigenes Handeln herbeiführen (Handlungs-Ergebnis-Erwartung)?

- Spielt der situative Kontext, in den man sich eingebunden fühlt, hierbei eine positive oder eine negative Rolle (Handlungs-bei-Situations-Erwartung)?

Darüber hinaus werden folgende Fragen dringlich:

- Stehen sowohl die zur Realisierung des Wunsches nötige Zeit als auch die Mittel zur Verfügung?

- Werden sich evtl. günstige Gelegenheiten anbieten?

Um die Wünschbarkeit eines potenziellen Ziels oder gegenwärtigen Wunsches zu bedenken, stellt sich ein Handelnder Fragen, wie z. B.:

- »Wenn ich tatsächlich versuche, dieses Ziel zu erreichen, welche kurz- und langfristigen Konsequenzen kommen dann auf mich zu?«

- »Wie positiv bzw. negativ können diese Konsequenzen für mich sein?

- »Wie hoch ist die Wahrscheinlichkeit, dass diese Konsequenzen auch wirklich eintreten werden?«

Die Beantwortung dieser Fragen geschieht, indem man durch die genannten Fragen den erwarteten Nutzen eines Wunsches bzw. potenziellen Ziels erwägt und sich Gedanken darüber macht, welche positiven und negativen, unmittelbaren und langfristigen Folgen mit welcher Wahrscheinlichkeit mit der Realisierung des Wunsches bzw. des potenziellen Ziels verknüpft sind. Hinsichtlich dieses Abwägens wird davon ausgegangen, dass ein Handelnder seine Wünsche und seine potenziellen Ziele nicht isoliert gegeneinander abwägt, sondern in Relation zueinander. Ein Wunsch, dessen Realisierung beispielsweise mit vielen positiven Folgeanreizen verknüpft ist, mag im Lichte eines übergeordneten anderen Wunsches plötzlich nicht mehr erstrebenswert erscheinen. Ande- rerseits mag die Realisierbarkeit eines bestimmten Wunsches im Rahmen der Verwirklichung anderer Wünsche leichter erscheinen als dies bei seiner isolierten Betrachtung der Fall gewesen wäre. Die Dauer des Abwägens variiert von Fall zu Fall. Selten werden alle Fragen geklärt; viele lassen sich auch gar nicht endgültig beantworten (so z. B. die Frage nach Ergebnis-Folge-Erwartungen, wenn es sich bei den in Frage stehenden Folgen um Fremdbewertungsanreize oder um die Annäherung an ein Oberziel handelt); meist steht nicht einmal ausreichend Zeit zur Verfügung, den potenziell beantwortbaren Fragen nachzugehen.

Das Rubikon-Modell postuliert deshalb die so genannte Fazittendenz. Dieses Konzept wurde im Rubikon-Modell entwickelt, um die Erledigung der motivationalen Aufgabe des Abwägens vorhersagen zu können. Je mehr ein Handelnder positive und negative kurz- und langfristige Konsequenzen möglicher Handlungen bzw. Nicht-Handlungen gegeneinander abgewogen hat, desto mehr gelangt er zur Überzeugung, die mögliche Elaboration der anstehenden Fragen ausgeschöpft zu haben. Die Aussicht auf neue Erkenntnisse über mögliche Konsequenzen sinkt also ab und umso stärker steigt die Fazittendenz an, d. h. die Tendenz, jetzt zu einem Entschluss hinsichtlich der Realisierung eines bestimmten Wunsches bzw. potenziellen Ziels zu kommen. Dieser Tendenz wird aber nur dann nachgegeben, wenn ein vorher festgesetztes erwünschtes Klärungsmaß erreicht worden ist. Hierbei korreliert die Höhe des gewünschten Klärungsausmaßes positiv mit der persönlichen Wichtigkeit der Entscheidung und negativ mit den Kosten, die das Beschaffen und Durchdenken von Informationen über mögliche Konsequenzen erfordert. Man kann den Prozess des Abwägens jedoch auch dadurch verkürzen, dass man sich intensiv und detailliert darüber Gedanken macht, wie eine der abzuwägenden Alternativen in die Tat umgesetzt werden könnte. Eine solche Vorwegnahme der Entscheidung und nachfolgenden Handlungsplanung erwies sich in einem Experiment von Gollwitzer, Heckhausen und Ratajczak (1990) als wirksames Mittel, Probanden näher an eine Entscheidung heran zu führen.

Damit ein Wunsch Zugang zur Exekutive und somit zu seiner Realisierung bekommt, genügt es jedoch nicht, dass beim Abwägen des Wunsches diesem eine vergleichsweise hohe resultierende Motivationstendenz (d. h. hoher erwarteter Nutzen und somit hohe Wünschbarkeit) attestiert und ihm damit die höchste Präferenz eingeräumt wird. Vielmehr bedarf es der Umwandlung des Wunsches in ein konkretes Ziel. Diese Umwandlung des Wunsches in ein Ziel wird häufig als das Überschreiten des Rubikons bezeichnet: Wie einst Julius Cäsar durch Überschreiten 
des Rubikons den Bürgerkrieg ausgelöst hatte, und sich jetzt bemühen musste, diesen zu gewinnen, so vollzieht sich mit der Umwandlung eines Wunsches in ein Ziel die Abkehr vom Abwägen des Nutzens eines Wunsches in ein Festlegen auf seine tatsächliche Realisierung. Deshalb spricht man auch vom Bilden einer "Zielintention" (zur Definition von "Zielintention" $>$ Abschn. 12.5). Das Ergebnis der Umwandlung des Wunsches in ein verbindliches Ziel bzw. in eine Zielintention ist auf der phänomenologischen Seite ein Gefühl des Entschlossenseins und der Handlungsgewissheit (Michotte \& Prüm, 1910). Das im Wunsch spezifizierte Ziel erwirbt starken Verbindlichkeitscharakter, so dass man sich dazu verpflichtet fühlt, es auch wirklich anzustreben.

( In der prädezisionalen Handlungsphase werden sowohl die Realisierbarkeit bestimmter Wünsche und Anliegen als auch die Wünschbarkeit potenzieller Handlungsergebnisse gegeneinander abgewogen. Durch diesen Abwägeprozess wird schließlich am Ende der prädezisionalen Handlungsphase ein verbindliches Ziel (Zielintention) gesetzt, das der Handelnde zu erreichen versucht - der »Rubikon« vom Wunsch zum Ziel wird überschritten. Hierbei entsteht ein Gefühl der Verpflichtung, dieses Ziel auch wirklich in die Tat umzusetzen - in der Forschung wird diese Verpflichtung »Commitment» genannt.

\section{Präaktionale Phase}

Neu gebildete Ziele lassen sich immer dann nicht unverzüglich in Angriff nehmen, wenn noch andere Handlungen eingeschoben oder abgeschlossen werden müssen, oder wenn erst noch eine geeignete Gelegenheit zum Handeln abgewartet werden muss. Viele Ziele spezifizieren obendrein Zielzustände (z. B. mehr Zeit mit der Familie verbringen; das Studium mit Erfolg abschließen etc.), die nicht auf Anhieb erreicht werden können. Folglich ergeben sich immer wieder Warteperioden, in denen günstige Gelegenheiten abgewartet werden müssen, die es erlauben, dem intendierten Zielzustand ein Stück näher zu kommen. Personen in diesem Wartestadium befinden sich laut Rubikon-Modell in der 2. Phase des Handlungsverlaufs - der präaktionalen (oder auch postdezisionalen) Handlungsphase, die als volitional bezeichnet wird. Der Terminus »Volition« soll darauf hindeuten, dass das motivationale Abwägen möglicher Handlungsziele durch Überschreiten des Rubikons beendet worden ist und jetzt die Realisierung des im Ziel spezifizierten Zielzustandes gewollt wird. In dieser postdezisionalen, aber noch präaktionalen Handlungsphase gilt es für einen Handelnden, sich Gedanken darüber zu machen, auf welche Weise er das am Ende der 1. Phase gesetzte Ziel auch wirklich realisieren will. Es geht also nicht mehr um die Wahl wünschenswerter und realisierbarer Ziele, sondern nun soll die Realisierung verbindlich gewordener Ziele mithilfe zielfördernder Handlungen vorangetrieben werden. Bei diesen Maßnahmen zur Realisierung von Zielen kann es sich sowohl um bereits routinierte und gut eingeübte Verhaltensweisen handeln, die mehr oder weniger automatisch ablaufen, aber auch um neue, noch nicht etablierte Verhaltensweisen, über die man sich zunächst noch Gedanken machen muss. Am günstigsten erweist es sich in dieser Phase, Pläne zu entwickeln, die bestimmen, wann, wo und auf welche Art und Weise man eine zielförderliche Handlung durchführen möchte (Gollwitzer, 1999). Solche
Pläne werden Vorsätze oder Durchführungsintentionen genannt ( Abschn. 12.5). Das Rubikon-Modell und die Theorie der intentionalen Handlungssteuerung (Gollwitzer, 1993, 1999) gehen davon aus, dass Vorsätze bezüglich der Initiierung, Durchführung und Beendigung von Handlungen Realisierungsschwierigkeiten zu überwinden helfen. Vor allem wird davon ausgegangen, dass Vorsätze primär für diejenigen Aspekte des Handlungsverlaufs gefasst werden, für die ein Handelnder potenziell Schwierigkeiten erwartet. Realisierungsschwierigkeiten sind insbesondere bei der Initiierung von Handlungen zu erwarten, da diese oft verpasst und auf die lange Bank geschoben wird. Häufig werden auch günstige Gelegenheiten, zielförderndes Verhalten zu initiieren, übersehen. Mit der Überwindung solcher Probleme ist ein Handelnder in der 2. Phase beschäftigt.

Wie kommt es nun zur Handlungsinitiierung, wenn eine mehr oder weniger günstige Gelegenheit zu handeln eintritt? Zur Beantwortung dieser Frage wurde das Konzept der Fiattendenz eingeführt: Beim Überschreiten des Rubikon erwerben Ziele einen Verbindlichkeitscharakter, so dass man sich jetzt verpflichtet fühlt, die damit korrespondierenden Zielzustände auch wirklich anzustreben. Die Stärke dieser Verpflichtung, die das RubikonModell Volitionstärke nennt, ist eine linear-positive Funktion der Stärke der zugehörigen Motivationstendenz (also der Wünschbarkeit und Realisierbarkeit des intendierten Zieles). Die Stärke der Fiattendenz einer bestimmten Zielintention ergibt sich nun aus dem Zusammenwirken ihrer Volitionsstärke (d. h. der Verpflichtung, den Zielzustand anzustreben) und dem Grad der Günstigkeit der vorliegenden Gelegenheit bzw. Situation zur Realisierung des intendierten Ziels. Die Günstigkeit der eingetretenen Situation wird allerdings nicht isoliert bestimmt, sondern im Vergleich zu anderen günstigen Gelegenheiten, das intendierte Ziel zu realisieren, die möglicherweise in Zukunft noch auftreten könnten (Längskonkurrenz). Aber auch die Fiattendenzen der einzelnen Ziele eines Handelnden sind in Relation zueinander zu sehen. Man darf also nicht davon ausgehen, dass es bei einem Ziel mit einer hohen Fiattendenz grundsätzlich zur Initiierung zielfördernder Handlungen kommt, denn viele Situationen sind nicht nur für die Verwirklichung eines einzigen Ziels günstig, sondern für viele andere Ziele auch. Liegt eine solche, für viele Ziele günstige Gelegenheit vor, können natürlich nicht all diese Ziele gleichzeitig realisiert werden. Man spricht in einem solchen Fall von Querkonkurrenz. Das Ziel mit der vergleichsweise höchsten Fiattendenz gewinnt nun den Zugang zur Exekutive und es werden Handlungen initiiert, die es letztlich realisieren sollen.

\footnotetext{
(D In der präaktionalen Handlungsphase überlegt sich ein Handelnder, welche Strategien er anwenden soll, um das in der prädezisionalen Handlungsphase verbindlich festgelegte Ziel auch wirklich zu realisieren und somit den erwünschten Zielzustand zu erreichen. In dieser Phase werden entsprechend Pläne (beispielsweise in Form von Vorsätzen oder Durchführungsintentionen ( Abschn. 12.5) entwickelt, die für das Erreichen des erwünschten Zielzustands förderlich erscheinen.
}

\section{Aktionale Phase}

Mit der Handlungsinitiierung zur Realisierung der in der präaktionalen Handlungsphase gefassten Pläne ist der Übergang in die aktionale Handlungsphase vollzogen. In dieser Phase versucht ein 
Handelnder, die geplanten zielfördernden Handlungen auch wirklich durchzuführen und sie zu einem erfolgreichen Ende zu bringen. Dies wird am besten durch ein beharrliches Verfolgen der Zielrealisierung ermöglicht, was eine Anstrengungssteigerung angesichts von Schwierigkeiten impliziert, sowie die konsequente Wiederaufnahme unterbrochener Zielhandlungen erfordert. Die Handlungsdurchführung wird von der Volitionsstärke des Ziels bestimmt. Die Höhe der Volitionsstärke stellt sozusagen einen Grenzwert für die Anstrengungsbereitschaft dar. Obwohl die Volitionsstärke primär von der Stärke der Motivationstendenz bestimmt ist, kann dieser Grenzwert durch Zusatzvolition nach oben verschoben werden. Die wichtigste Quelle der Zusatzvolition ist die beim Überwinden von Schwierigkeiten mobilisierte reaktive Anstrengungsbereitschaft. Geleitet wird die Handlungsdurchführung in dieser Phase des Handlungsverlaufs durch die mentale Repräsentation des Ziels auf welches ein Handelnder sich verpflichtet hat. Hierbei ist die Repräsentation des Ziels nicht bewusstseinspflichtig, d. h. das Ziel muss nicht im Bewusstsein gegenwärtig sein.

( In der aktionalen Handlungsphase versucht ein Handelnder, die in der präaktionalen Handlungsphase gefassten Pläne zur Realisierung des am Ende der prädezisionalen Handlungsphase gefassten Ziels in die Tat umzusetzen. Dies wird am besten durch beharrliches Verfolgen des Ziels und durch Anstrengungssteigerung bei Auftreten von Schwierigkeiten erreicht.

\section{Postaktionale Handlungsphase}

Für die 4. und somit letzte Phase des Handlungsverlaufs, nämlich der postaktionalen Handlungsphase, wird angenommen, dass sie nach dem Abschluss der auf die Realisierung des Ziels gerichteten Handlungen eintritt. Nun gilt es für einen Handelnden wieder eine motivationale Aufgabe zu bewältigen. Es wird angenommen, dass dieser jetzt die Ergebnisse seiner realisierten Pläne mit Hinblick auf das vormals am Ende der prädezisionalen Handlungsphase gesetzte Ziel bewertet:

- Wie gut habe ich es geschafft dieses Ziel zu erreichen?

- Sind die erhofften positiven Konsequenzen meines Handelns auch wirklich eingetroffen?

- Kann ich meine Handlungsintention nun als erledigt betrachten?

- Ist es notwendig, bei Nichterreichen des Ziels dieses weiterhin und möglicherweise mit anderen Mitteln zu verfolgen?

Dieses Abwägen basiert einerseits auf einem Blick zurück auf das nun vorliegende Handlungsergebnis, ist andererseits aber auch gleichzeitig nach vorne auf zukünftiges Handeln gerichtet. Entspricht das erzielte Handlungsergebnis dem erwünschten Zielzustand, findet eine Deaktivierung des zugrunde liegenden Ziels statt. Dabei werden häufig Defekte der motivationalen Elaboration (d. h. des Abwägens positiver und negativer, kurz- und langfristiger Konsequenzen) in der prädezisionalen Handlungsphase offenbar. So kann sich beispielsweise zeigen, dass man die Wünschbarkeit des Ziels zu positiv eingeschätzt hat, weil man bestimmte Ergebnis-Folge-Erwartungen im Vorfeld zu hoch angesetzt oder aber gar nicht berücksichtigt hat. Natürlich führen aber nicht alle Vergleiche zwischen intendiertem und erzieltem Handlungsergebnis zu einer Deaktivierung des Ziels, da das erzielte Handlungsergebnis in qualitativer oder quantitativer Hin- sicht häufig von diesem abweicht. Dies kann nun dazu führen, dass das Ziel durch eine Senkung des Anspruchsniveaus an das erzielte Handlungsergebnis angepasst wird. Wird dagegen das ursprüngliche Ziel trotz eines nicht zufrieden stellenden Handlungsergebnisses beibehalten, müssen neue Handlungen in Angriff genommen werden, um zu versuchen, das Ziel letztlich doch noch zu erreichen. Für eine erfolgreiche Deaktivierung eines nicht erreichten Handlungsziels scheint es förderlich zu sein, wenn der Handelnde ein neues Ziel vor Augen hat, das das nicht erreichte Ziel ersetzen kann. So konnte Beckmann (1994) zeigen, dass nur solche Probanden sich erfolgreich mental von einem missglückten Intelligenztest lösen konnten, die erwarteten, in der nächsten Runde einen neuen Test bearbeiten zu können. Probanden, denen diese Aussicht nicht offeriert worden war, blieben in ihren Gedanken dem schlechten Testergebnis und entsprechenden Selbstbewertungsruminationen verhaftet.

( In der postaktionalen Handlungsphase bewertet ein Handelnder sein erreichtes Handlungsergebnis. Ist er mit diesem zufrieden, deaktiviert er das am Ende der prädezisionalen Handlungsphase gesetzte Ziel. Ist er mit diesem Handlungsergebnis nicht zufrieden, senkt er entweder sein Anspruchsniveau und deaktiviert das Ziel oder er behält dieses bei und plant neue Handlungen, die dafür geeignet erscheinen, den erwünschten Zielzustand doch noch zu erreichen.

\subsubsection{Motivationale vs. volitionale Handlungsphasen}

Als »Volition « wird von Kurt Lewin (1926b) und Narziß Ach (1935) diejenige Form der Motivation verstanden, die sich auf das Streben nach Zielen bezieht. Unter Zielstreben ("goal striving «) werden alle motivationsregulatorischen Phänomene verstanden, die sich um das Erreichen vorhandener Ziele drehen. Somit steht bei der Volition die Frage im Vordergrund, wie die handelnde Umsetzung einer bereits gesetzten Zielintention reguliert wird. Der Terminus » Motivation « wird dagegen für motivationale Prozesse benutzt, welche das Setzen von Zielen (»goal setting«) betreffen. Hier geht es also um die Frage, welche Ziele eine Person anstreben will. Es wird angenommen, dass Personen, die sich zwischen verschiedenen Zielen entscheiden müssen, dem erwarteten Wert und der Erreichbarkeit der verfügbaren Optionen, zwischen denen man sich entscheiden kann, starke Beachtung schenken (Gollwitzer, 1990). Klassische Motivationstheorien halten an dieser engen Definition von Motivation in dem Sinne fest als sie annehmen, dass die Motivation zu handeln sowohl durch die Wünschbarkeit (»desirability «) des jeweils angestrebten Ziels als auch durch seine wahrgenommene Realisierbarkeit (»feasibility «) bestimmt wird. Wenn eine Person der Meinung ist, dass sie die für die Zielerreichung erforderlichen Handlungen nicht bewältigen kann oder sie das ins Auge gefasste Ziel für nicht besonders wünschenswert hält, wird sie nicht dazu motiviert sein, das Ziel auch wirklich anzustreben.

In den frühen 80er-Jahren des letzten Jahrhunderts griff Kuhl die Unterscheidung zwischen Motivation und Volition wieder auf und setzte die moderne Volitionsforschung explizit ab von der philosophisch geprägten Debatte um den »freien Willen « (Kuhl, 1983; auch Kap. 13). Kuhl wies als erster moderner Motivations- 
forscher auf die gegensätzlichen Funktionen und Charakteristika von Selektions- und Realisationsmotivation hin und setzte sich mit Nachdruck dafür ein, dass in der Forschung zwischen motivationalen und volitionalen Fragen unterschieden wird (Kuhl, 1983, 1984, 1987).

\section{Zusammenfassung \\ Der Begriff Motivation bezieht sich auf Prozesse und Phäno- mene, die mit dem Setzen von Zielen aufgrund deren Wünschbarkeit und Realisierbarkeit zu tun haben. Motiva- tionale Prozesse dominieren in der prädezisionalen und in der postaktionalen Handlungsphase des Rubikon-Modells. Der Begriff Volition bezieht sich dagegen auf Prozesse und Phänomene, die mit der konkreten Realisierung von Zielen im Handeln zu tun haben. Volitionale Prozesse finden in der präaktionalen und in der aktionalen Handlungsphase statt.}

\subsection{Handlungsphasen und Bewusstseins- lagen oder die Frage "Wie bringt man psychologische Prozesse in ein idealtypisches, strukturelles Modell?»}

Das Rubikon-Modell der Handlungsphasen impliziert, dass sich zielgerichtetes Verhalten in eine Abfolge verschiedener Phasen aufgliedern lässt. Diese Einteilung in verschiedene Phasen macht aber nur dann Sinn, wenn diese qualitativ unterschiedliche psychologische Phänomene beschreiben können. Diese unterschiedlichen psychologischen Phänomene der verschiedenen Handlungsphasen entsprechen den unterschiedlichen Funktionen der Handlungsphasen, so dass es sich beim Rubikon-Modell um ein strukturfunktionales Modell handelt (Heckhausen, 1987a). Die wesentlichen Funktionen der verschiedenen Handlungsphasen sind in der folgenden Übersicht aufgeführt.

\section{Funktionen der Handlungsphasen im Rubikon-Modell}

- Prädezisionale Handlungsphase: Abwägen

- Postdezisionale, präaktionale Handlungsphase: Vorbereiten und Planen

- Aktionale Handlungsphase: Handeln

- Postaktionale Handlungsphase: Bewerten

Diesen Funktionen entsprechen unterschiedliche Bewusstseinslagen, bei denen Information in einer auf die Handlungsphase funktional abgestimmten Weise verarbeitet wird. Das Konzept der »Bewusstseinslage « bezeichnet in Anlehnung an den Sprachgebrauch der Würzburger Schule ( Kap. 2) Bewusstseinszustände, die sich bei der Übernahme und Ausführung einer Aufgabe einstellen (Marbe, 1915; Heckhausen, 1989).

\section{Definition}

Unter dem Begriff »Bewusstseinslage« versteht man eine bestimmte Art von kognitiver Orientierung, die für die Erledigung der jeweils in einer bestimmten Handlungsphase anstehenden Aufgabe erforderlich ist.
Der Hintergrund für die Bewusstseinslagenforschung ist die Idee, dass in jeder Handlungsphase des Rubikon-Modells eine distinkte Aufgabe zu lösen ist (Gollwitzer, 1990).

In einem umfassenden Forschungsprogramm belegten Gollwitzer und Mitarbeiter ( Übersicht in Gollwitzer, 1991) die qualitativen Unterschiede zwischen verschiedenen Handlungsphasen und zeigten, dass in den verschiedenen Handlungsphasen unterschiedliche funktionsabgestimmte Bewusstseinslagen Inhalt und Form der Informationsverarbeitung bestimmen. Genauer gesagt begründete Gollwitzer ein Forschungsparadigma, nach dem durch eine Analyse der jeweiligen Aufgabenanforderungen beim Abwägen, Planen, Handeln und Bewerten spezifische Hypothesen über die Unterschiedlichkeiten der Informationsverarbeitung in den einzelnen Handlungsphasen abgeleitet und dann gezielt überprüft werden können (Gollwitzer, 1990; Gollwitzer \& Bayer, 1999). Diese Hypothesen beziehen sich auf die kognitiven Orientierungen, die für die Lösung der jeweiligen phasenspezifischen Aufgaben funktional sind. Es wird davon ausgegangen, dass jede Handlungsphase mit einer bestimmten Bewusstseinslage (d. h. mit der Aktivierung spezieller kognitiver Prozeduren) einhergeht, welche die jeweils im Handlungsverlauf aktuell erforderliche Aufgabe unterstützt.

\section{Abwägende Bewusstseinslage}

Die abwägende Bewusstseinslage tritt in der prädezisionalen Handlungsphase auf und ist folglich mit der Aufgabe des Setzens von Zielen beschäftigt. Durch welche kognitive Orientierung zeichnet sich diese Bewusstseinslage aus? Wie gestaltet sich die Aufnahme von Informationen in dieser Bewusstseinslage und wie werden diese Informationen verarbeitet? Die Aufgabe, die es in der prädezisionalen Handlungsphase zu lösen gilt ist die, zwischen einer Vielzahl anstehender Wünsche jeweils denjenigen auszuwählen, den man letztlich in die Tat umsetzen möchte. Die Wahl relativ attraktiver und erreichbarer Handlungsziele erfordert das vergleichende Abwägen der Wünschbarkeit und Realisierbarkeit dieser Wünsche. Damit erfordert die Auswahl eines Handlungsziels die Aufnahme und Verarbeitung von Informationen über Anreize (Wünschbarkeit) und Erwartungen (Realisierbarkeit). In der abwägenden Bewusstseinslage sollten diese Arten von Informationen insofern bevorzugt verarbeitet werden. Weiterhin gilt es in dieser Handlungsphase positive und negative Anreize bzw. Konsequenzen möglicher Handlungsergebnisse möglichst unparteiisch gegeneinander abzuwägen, d. h. auch Überlegungen hinsichtlich negativer Anreize sollten nicht unter den Tisch fallen. Genauso sollten Einschätzungen der Realisierbarkeit eines Wunsches möglichst korrekt ausfallen, d. h. sie sollten nicht zu optimistisch, aber auch nicht zu pessimistisch ausfallen. Nur wenn Erwartungen und Anreize objektiv und ausgewogen eingeschätzt werden, kann die prädezisionale Aufgabe, nämlich ein vergleichsweise wünschenswertes und realisierbares Ziel auszuwählen, mit Erfolg gelöst werden.

\section{Planende Bewusstseinslage}

Die planende Bewusstseinslage tritt in der präaktionalen Handlungsphase auf, entsprechend ist ihre Aufgabe die Vorbereitung der Realisierung von Zielen. Diese kann vorangetrieben werden, indem man sich um die Initiierung relevanter Handlungen 
bemüht. Wie das konkret aussieht, hängt von der Art des gesetzten Ziels ab: Wurde dieses beim Überschreiten des Rubikons mit Vorsätzen ( $\$ Abschn. 12.5-12.7) ausgestattet, die sich darauf beziehen, wo und wann welche Handlungen initiiert werden sollen, so geht es nur noch darum, die definierte Gelegenheit zum Handeln (d. h. das im Vorsatz festgelegte »wann « und »wo « man handeln will) abzuwarten. Tritt eine potenziell günstige Gelegenheit zum Handeln ein, prüft ein Handelnder, inwiefern für ihn die als günstig definierte Gelegenheit vorliegt. Ergibt sich hierbei eine Passung zwischen der als günstig definierten Gelegenheit und der tatsächlich eintretenden Gelegenheit, dann erfolgt sofort die Initiierung zielfördernden Verhaltens. Ähnliches gilt für Ziele, bei denen Vorsätze nicht erforderlich sind, da bei ihnen gewohnheitsmäßig nur eine ganz bestimmte Art der Handlungsinitiierung denkbar ist. Auch in diesem Fall muss ein Handelnder nur das Eintreten der passenden Gelegenheit zur Initiierung zielfördernden Verhaltens abwarten. Liegen weder Vorsätze noch Gewohnheiten vor, die die Realisierung des Ziels möglich machen können, müssen erst einmal Vorsätze oder Pläne gefasst werden, die darauf abzielen, das Ziel zu realisieren. Die für diese Aufgaben erforderliche kognitive Orientierung soll gewährleisten, dass bevorzugt Informationen aufgenommen und verarbeitet werden, die den Beginn zielrealisierenden Verhaltens begünstigen, so dass ein Aufschub der Zielrealisierung vermieden wird. In diesem Sinne werden bevorzugt Informationen aufgenommen, die darüber Auskunft geben, wo, wann und wie Handlungen initiiert werden können, die die Realisierung des Ziels vorantreiben. Gleichzeitig sollte sich der Fokus der Aufmerksamkeit verengen, so dass bei der Bearbeitung einer Aufgabe nur noch ganz zentrale Bearbeitungshinweise verarbeitet und periphere, weniger relevante Bearbeitungshinweise ignoriert werden. Dadurch soll gewährleistet werden, dass eine günstige Gelegenheit auch sofort erkannt wird, da ein Handelnder durch die Fokussierung der Aufmerksamkeit vor Ablenkung durch Informationen über konkurrierende Ziele etc. geschützt ist. Diese Abschirmung betrifft auch Informationen hinsichtlich der Wünschbarkeit und Realisierbarkeit desjenigen Ziels für dessen Realisierung ein Handelnder sich am Ende der prädezisionalen Phase entschieden hatte. Informationen über die Wünschbarkeit und Realisierbarkeit dieses Ziels sind für die Initiierung zielfördernden Verhaltens irrelevant, ja sogar störend.

(8) In der planenden Bewusstseinslage werden also Informationen, die sich auf die Initiierung zielfördernden Verhaltens beziehen, besonders effektiv aufgenommen. Gleichzeitig zeigt sich bei der Aufnahme von Informationen aber eine Verengung des Aufmerksamkeitsfokus, wodurch nur für die Realisierung des Ziels erforderliche Informationen verarbeitet werden.

\section{Aktionale Bewusstseinslage}

Die aktionale Bewusstseinslage tritt in der aktionalen Handlungsphase auf. Hier gilt es die Realisierung des Ziels erfolgreich zu Ende zu führen. Dabei sollten Unterbrechungen zielfördernden Verhaltens vermieden werden, da jedes Stocken des Handlungsflusses die Zielerreichung hinausschiebt. Die aktionale Bewusstseinslage sollte deshalb durch Aspekte gekennzeichnet sein, die Csikszentmihalyi (1975) der so genannten »flow experience« und Wicklund (1986) der so genannten »dynamic orientation « zuschreibt. Das bedeutet konkret, dass ein Handelnder, der sich in dieser Bewusstseinslage befindet, weder an das zu realisierende Ziel, noch daran denkt, ob er die erforderlichen Fähigkeiten und Fertigkeiten für die Realisierung dieses Ziels besitzt. Der Handelnde überlegt weder ob es sinnvoll wäre, andere zielfördernde Verhaltensweisen anstelle der aktuellen zu zeigen, noch fasst er sich Vorsätze bzw. Handlungspläne, um festzulegen, wann, wo und wie er handeln will. Ein Handelnder ist stattdessen völlig mit den Handlungen beschäftigt, die er gerade ausführt und geht völlig in diesen auf. Dementsprechend werden nur diejenigen Aspekte des Selbst und der Umgebung beachtet, die den Handlungsablauf unterstützen. Aspekte, die zu Unterbrechungen des Handlungsablaufs wie z. B. selbstreflektierende Gedanken, konkurrierende Ziele oder ablenkende Umweltreize führen könnten, werden dagegen ignoriert. Damit ist die aktionale Bewusstseinslage hypothetisch auch durch die Verweigerung der Aufnahme und Analyse von Informationen gekennzeichnet, die sich auf eine Neubewertung des am Ende der prädezisionalen Handlungsphase ausgewählten Ziels bezieht, auf eine Neubewertung der gewählten Handlungsstrategie, oder auf irgendeine Selbstbewertung (z. B.: Kann ich auf meine bisherige Leistung stolz sein? Besitze ich die zur Zielrealisierung notwendigen Fähigkeiten?). Weiterhin sollte die aktionale Bewusstseinslage durch die bevorzugte Aufnahme von Informationen gekennzeichnet sein, die sich auf internale und externale Aspekte bezieht, die den Handlungsverlauf in Richtung auf die Realisierung des Ziels steuern. Diese Informationen sollten möglichst genau sein und nicht ins Positive verzerrt ausgewertet werden. Die aktionale Bewusstseinslage sollte immer dann entstehen, wenn man sich reibungslos auf die Verwirklichung eines Ziels hinbewegt.

\section{Bewertende Bewusstseinslage}

Die bewertende Bewusstseinslage sollte in der postaktionalen Handlungsphase entstehen. In dieser gilt es, das Handlungsergebnis und seine Folgen zu bewerten. Es geht darum, herauszufinden, ob die durch die Realisierung des Ziels intendierten Handlungsergebnisse auch tatsächlich erreicht worden sind und ob die erwarteten Konsequenzen auch wirklich eintraten. Aus diesem Grund setzt man sich in der bewertenden Bewusstseinslage primär mit der Qualität des erzielten Handlungsergebnisses und der tatsächlichen Attraktivität der eingetretenen Konsequenzen auseinander. Die Lösung der Aufgabe in der bewertenden Handlungsphase impliziert einen einfachen Vergleich zwischen dem, was erreicht (Ergebnisse), dem, was erhalten wurde (Folgen), sowie dem, was ursprünglich erwartet bzw. beabsichtigt worden war. Dies setzt eine korrekte Einschätzung der Qualität des Ergebnisses und eine objektive, unparteiische Beurteilung der Attraktivität seiner Folgen voraus. Insofern sollte die bewertende Bewusstseinslage folgende Merkmale aufweisen:

- Eine bevorzugte Aufnahme von Informationen, die für die Einschätzung des erzielten Ergebnisses und der Wünschbarkeit der Folgen relevant ist,

- eine unparteiische und genaue Informationsverarbeitung, sowie

- eine vergleichende Orientierung: Das intendierte Ergebnis und dessen erwartete Konsequenzen werden mit dem tatsächlich erzielten Ergebnis und dessen Konsequenzen verglichen. 


\begin{abstract}
Zusammenfassung
Die verschiedenen Handlungsphasen des Rubikon-Modells differenzieren vier eigenständige Phänomene zielorientierten Verhaltens: Abwägen, Planen, Handeln und Bewerten. Da jedes dieser Phänomene die Bearbeitung einer jeweils anderen Aufgabe impliziert, entstehen verschiedene Bewusstseinslagen, wenn die Lösung dieser Aufgaben in Angriff genommen wird. Die kognitiven Merkmale dieser Bewusstseinslagen lassen sich durch detaillierte Analysen der jeweiligen konkreten Aufgabenanforderungen spezifizieren. So beinhaltet die abwägende Bewusstseinslage eine Offenheit für eine objektive Verarbeitung aller Informationen hinsichtlich der potenziellen Konsequenzen eines Handlungsergebnisses (Wünschbarkeit) sowie der Realisierbarkeit der zur Debatte stehenden Wünsche (Durchführbarkeit). Die kognitive Orientierung der planenden Bewusstseinslage soll gewährleisten, dass bevorzugt Informationen aufgenommen werden, die den Beginn zielrealisierenden Verhaltens begünstigen, so dass ein Aufschub der Zielrealisierung vermieden wird. Die aktionale Bewusstseinslage begünstigt die Beachtung nur derjenigen Aspekte des Selbst und der Umgebung, die den Handlungsablauf unterstützen. Aspekte, die zu Unterbrechungen des Handlungsablaufs wie beispielsweise selbst reflektierende Gedanken, konkurrierende Ziele oder ablenkende Umweltreize führen könnten, werden dagegen ignoriert. In der bewertenden Bewusstseinslage ist die kognitive Orientierung so ausgerichtet, dass möglichst objektiv und genau das erreichte Handlungsergebnis bewertet wird. Es erfolgt in diesem Sinne ein Vergleich zwischen dem, was erreicht (Handlungsergebnis) und dem, was erhalten wurde (Konsequenz des Handlungsergebnisses), sowie dem, was ursprünglich an Konsequenzen erwartet bzw. beabsichtigt worden war.
\end{abstract}

\subsection{Unterschiedliche Effekte der Bewusst- seinslagen des Abwägens und Planens}

Nachdem in Abschn. 12.3 der theoretische Hintergrund für die vier Bewusstseinslagen diskutiert wurde, erfolgt nun die Darstellung empirischer Befunde, welche die aufgestellten theoretischen Überlegungen zur kognitiven Orientierung der abwägenden und der planenden Bewusstseinslage stützen. Die Erforschung der Informationsverarbeitungsprozesse, der postulierten Prozesse und Phänomene der kognitiven Orientierung sowie der aktionalen und der bewertenden Bewusstseinslage steht noch aus. Im Folgenden wird beschrieben, wie die abwägenden und planenden Bewusstseinslagen experimentell induziert werden können:

\subsubsection{Kognitives Tuning auf aufgabenkongruente Informationen}

Die planende Bewusstseinslage unterstützt das Erreichen von Zielen, indem sie dabei hilft, die klassischen Probleme des Zielstrebens, wie das Anzweifeln der Attraktivität und somit der Wünschbarkeit des verfolgten Ziels oder den Pessimismus hin- sichtlich der Durchführbarkeit zielfördernder Strategien bzw. der Realisierbarkeit des angestrebten Anliegens, zu bewältigen. Diese Überlegung stützend wurde herausgefunden, dass Informationen, die mit der konkreten Realisierung des angestrebten Anliegens zu tun haben, in der planenden Bewusstseinslage bevorzugt verarbeitet werden. So berichteten Versuchspersonen, bei denen eine planende Bewusstseinslage induziert worden war, von mehr Gedanken über die konkrete Realisierung ihres angestrebten Anliegens (d. h. "planende « Gedanken mit dem Format »Ich werde mit X beginnen und dann Y tun!«) als Versuchspersonen, die sich in einer abwägenden Bewusstseinslage befanden (d. h. »abwägende « Gedanken mit dem Format »Wenn ich dies tue, dann hat das diese positiven/negativen Konsequenzen zur Folge, wenn ich es nicht tue, dann geschieht vermutlich dieses und jenes... «; vgl. Heckhausen \& Gollwitzer, 1987; Taylor \& Gollwitzer, 1995, Studie 3; Puca \& Schmalt, 2001).

In einer Reihe von Studien induzierten Gollwitzer, Heckhausen und Steller (1990) entweder die planende Bewusstseinslage oder die abwägende Bewusstseinslage auf die in Abschn. 12.4 beschriebene Art und Weise. Anschließend wurden den Versuchspersonen schriftlich Märchen vorgelegt, die unvollendet waren. In einem angeblichen Kreativitätstest sollten die Versuchspersonen einen Schluss für diese Märchen schreiben. Versuchspersonen, die sich in der planenden Bewusstseinslage befanden, erfanden hierbei häufiger Protagonisten, die versuchten, das Erreichen eines bestimmten Ziels zu planen als Versuchspersonen, die sich in der abwägenden Bewusstseinslage befanden. In einer weiteren Studie betrachteten Versuchspersonen Dias, nachdem entweder die abwägende oder die planende Bewusstseinslage induziert worden war. Jedes Dia präsentierte verschiedene Sätze, die Informationen hinsichtlich der Gedanken einer anderen Person enthielten und die sich entweder auf das Abwägen einer Zielsetzung oder auf die Realisierung eines gewählten Ziels bezogen. Nach dem Betrachten der Dias und der Durchführung einer kurzen Ablenkaufgabe erledigten die Versuchspersonen einen Erinnerungstest bezüglich der auf den Dias präsentierten Informationen. Versuchspersonen der planenden Bewusstseinslage konnten die auf den Dias präsentierten Sätze, die sich auf das Planen von Handlungen bezogen, besser erinnern als die Sätze, die sich auf das Abwägen von Handlungen bezogen. Das Umgekehrte galt für Versuchspersonen der abwägenden Bewusstseinslage.

\footnotetext{
Zusammenfassung

In der abwägenden Bewusstseinslage drehen sich die Gedanken eines Handelnden stärker um das Abwägen von Handlungsalternativen als in der planenden Bewusstseinslage. Genauso werden Informationen, die mit dem Abwägen von Alternativen assoziiert sind besser erinnert als Informationen, die mit dem Planen von zielfördernden Handlungen in Verbindung stehen. In der planenden Bewusstseinslage macht sich ein Handelnder mehr Gedanken, die mit dem Planen zielfördernder Verhaltensweisen als mit dem Abwägen zu tun haben. Gleichzeitig erinnert er auch Informationen, die mit dem Planen von Handlungen zu tun haben besser als Informationen, die mit dem Abwägen von Handlungsalternativen zu tun haben.
} 
Experimentelle Anordnungen zur Erfassung abwägender und planender Bewusstseinslagen

- Induktion der abwägenden Bewusstseinslage:

Versuchspersonen werden gebeten, ein persönliches Anliegen (Problem) zu nennen, hinsichtlich dessen sie sich noch nicht sicher sind, ob sie es realisieren wollen (d. h. ob sie handeln sollen) oder den Dingen einfach freien Lauf lassen sollen, ohne selbst aktiv in die Geschehnisse einzugreifen (d. h. ob sie nicht handeln sollen). Bei einem solchen Anliegen kann es sich z. B. um die Frage handeln, ob es sinnvoll ist den Studiengang zu wechseln oder ob es besser ist im derzeitigen Studiengang zu bleiben. Nach der Nennung eines persönlichen Anliegens listen die Versuchspersonen kurzfristige und langfristige, positive und negative Konsequenzen einer Entscheidung zum Handeln bzw. zum Nichthandeln auf und schätzen ein, wie hoch die Wahrscheinlichkeit ist, dass diese Konsequenzen auch wirklich eintreten werden (vgl. Gollwitzer \& Kinney, 1989, Studie 2; Gollwitzer \& Bayer, 1999).

- Induktion der planenden Bewusstseinslage:

Dabei werden die Versuchspersonen gebeten, zunächst ein Ziel (Projekt) zu nennen, das sie innerhalb der nächsten 3 Monate zu realisieren beabsichtigen. Bei einem solchen Ziel kann es sich z. B. darum handeln, ein Stipendium für ein Auslandsstudium zu beantragen. Anschließend sollen die Versuchspersonen 5 Handlungsschritte auflisten, die letztlich dazu führen sollen, das angestrebte Ziel auch wirklich zu erreichen. Jeder einzelne Handlungsschritt wird anschließend dahingehend ausgearbeitet, wann, wo und auf welche Art und Weise es realisiert werden soll. Dadurch legt der Handelnde genau fest, zu welcher Zeit, an welchem Ort und wie er die einzelnen Handlungsschritte, die letztlich zur Realisierung des Ziels führen sollen, durchführen will (vgl. Gollwitzer \& Kinney, 1989, Studie 2; Gollwitzer \& Bayer, 1999).

- Alternative Induktionsmöglichkeiten: Puca (2001) und Puca und Schmalt (2001) manipulierten das Eintreten einer abwägenden Bewusstseinslage, indem sie Versuchspersonen, die kurz vor dem Treffen einer Entscheidung standen, in ihrem Entscheidungsfindungsprozess unterbrachen und somit im Abwägen über zu wählende Alternativen verharren ließen. Die planende Bewusstseinslage induzierten sie, indem sie Versuchspersonen ihre Entscheidung treffen ließen (sie durften zwischen Alternativen wählen). Die jeweilige Entscheidungsaufgabe hatte hierbei inhaltlich nichts mit den nachfolgenden Aufgaben zu tun, sondern diese nachfolgenden Aufgaben dienten dazu, den Effekt der jeweiligen Bewusstseinslage auf verschiedene kognitive Prozesse zu untersuchen. Ähnlich gingen bereits Gollwitzer und Kinney vor (1989, Studie 1). Auch sie präsentierten ihren Versuchspersonen ein Entscheidungsproblem, um sie entweder in die planende oder in die abwägende Bewusstseinslage zu versetzen. Die planende Bewusstseinslage wurde in dieser Studie induziert, indem die Versuchspersonen sich vor Erhebung der interessierenden abhängigen Variablen definitiv für eine bestimmte Reihenfolge von Versuchsdurchgängen entscheiden mussten. Die abwägende Bewusstseinslage wurde induziert, indem die Versuchspersonen kurz vor ihrer definitiven Entscheidung für eine bestimmte Reihenfolge von Versuchsdurchgängen in ihrem Entscheidungsprozess unterbrochen wurden.

\subsubsection{Verarbeitung relevanter und irrelevanter Informationen}

Gollwitzer und Bayer (1999) berichten, dass die planende Bewusstseinslage zu einer »closed-mindedness « in dem Sinne führt, dass ein Handelnder, wenn er sich in dieser Bewusstseinslage befindet, nicht mehr länger durch irrelevante Informationen vom Zielstreben abgelenkt werden kann, sondern sich nur noch auf Informationen konzentriert, die für die Realisierung seines Anliegens relevant sind. Dieser Befund wird auch durch Ergebnisse einer Studie von Heckhausen und Gollwitzer (1987, Studie 2) unterstützt, die zeigen konnten, dass Versuchspersonen in einer planenden Bewusstseinslage eine engere Wort-Gedächtnisspanne aufweisen (ein guter Indikator für reduzierte kognitive Verarbeitungsgeschwindigkeit; Dempster, 1985) als Versuchspersonen in einer abwägenden Bewusstseinslage. Schließlich konnte in einer Reihe von Studien mithilfe einer modifizierten Müller-Lyer-Aufgabe gezeigt werden, dass die planende Bewusstseinslage mit einer stärker zentral fokussierten Aufmerksamkeitsverteilung einhergeht als die abwägende Bewusstseinslage. Die abwägende Bewusstseinslage führte dagegen erwartungsgemäß im Vergleich zur planenden Bewusstseinslage zu einer peripheren Aufmerk- samkeitsverteilung (Gollwitzer \& Bayer, 1999). Drei Studien welche die selektive Verarbeitung von beiläufig präsentierten Informationen untersuchten, bestätigten ebenfalls die Annahme einer »open-mindedness « in der abwägenden und einer »closed-mindedness « in der planenden Bewusstseinslage (Fujita, Gollwitzer \& Oettingen, 2007). Hier konnte eine höhere Wiedererkennungsleistung für beiläufig präsentierte Informationen in einer abwägenden Bewusstseinslage im Vergleich zu einer planenden Bewusstseinslage beobachtet werden, was die Annahme einer breit gestreuten Aufmerksamkeit in der abwägenden Bewusstseinslage belegt. Beckmann und Gollwitzer (1987) konnten in einem Entscheidungsexperiment zwischen Rubikon-Modell und Festingers Dissonanztheorie sogar zeigen, dass in der planenden Bewusstseinslage handlungsrelevante Informationen selbst dann bevorzugt verarbeitet werden, wenn diese gegen die getroffenen Handlungsentscheidungen sprechen. In einer Reihe von Studien zur Auswirkung der planenden Bewusstseinslage auf die Stärke von Einstellungen wurden folgende Effekte beobachtet: Die Einstellungen wurden extremer, die Einstellungsambivalenz nahm ab, die Einstellung wurde kognitiv zugänglicher und - was mit der interessanteste Punkt für die Einstellungsforschung ist - die Korrespondenz zwischen Einstellung und dem dazugehörigen Ver- 
halten erhöhte sich (Henderson, Gollwitzer \& de Liver, 2008). Henderson et al. (2008) interpretieren diese Effekte der planenden Bewusstseinslage (in der abwägenden Bewusstseinslage wurden diese nicht beobachtet), dass diese die Bewertung von Informationen in eine Richtung begünstigt. Diese durch das Planen ausgelöste Tendenz, Dinge eher einseitig zu beurteilen, wirkt sich auf Einstellungen dann auf die beschriebene Art und Weise aus.

\section{Zusammenfassung \\ Empirische Befunde konnten zeigen, dass die abwägende Be- wusstseinslage dazu führt, dass man sich eher von Informa- tionen ablenken lässt, die für die Realisierung von Zielen irre- levant sind. Das ist in Übereinstimmung mit der Beobach- tung, dass eine abwägende Bewusstseinslage mit einer peripheren Aufmerksamkeitsverteilung einhergeht. Umge- kehrtes gilt für die planende Bewusstseinslage: Hier werden hauptsächlich Informationen verarbeitet, die für die Realisie- rung eines Ziels relevant sind und es findet eine Fokussierung der Aufmerksamkeit statt.}

\subsubsection{Verzerrte Verarbeitung relevanter Infor- mationen hinsichtlich der Realisierbarkeit und Wünschbarkeit eines Ziels}

In der Bewusstseinslagenforschung wird angenommen, dass die planende Bewusstseinslage eine positive Bewertung des gewählten Ziels (d. h. eine hohe Wünschbarkeit dieses Ziels) fördert und gleichzeitig auch einen hohen Optimismus hinsichtlich der Durchführbarkeit und Erreichbarkeit dieses Ziels unterstützt. Da- gegen wurde angenommen, dass die abwägende Bewusstseinslage eine objektive Einschätzung positiver und negativer Konsequenzen der Erreichung eines Ziels, sowie eine genaue Bewertung der Wahrscheinlichkeit, dieses Ziel auch zu erreichen, generiert. Um diese Hypothesen zu überprüfen, sind verschiedene Studien (vgl. Gollwitzer, 1990) durchgeführt worden. Im Folgenden wird eine der klassischen Studien zu dieser Thematik dargestellt.

Zum Thema "illusionärer Optimismus« in der planenden Bewusstseinslage berichten Gagné und Lydon (2001a), dass Versuchspersonen in der planenden Bewusstseinslage die Fortführung ihrer aktuellen Partnerschaften optimistischer beurteilen als Versuchspersonen in der abwägenden Bewusstseinslage. Ähnlich stellte auch Puca (2001, Studie 1 und 2) fest, dass die planende Bewusstseinslage eine optimistische Orientierung bei der Auswahl von Testmaterial unterschiedlichen Schwierigkeitsgrades (Studie 1) und bei der Vorhersage eigener zukünftiger Leistungen (Studie 2) induziert. Im Vergleich zu Versuchspersonen in einer abwägenden Bewusstseinslage findet sich für Versuchspersonen in einer planenden Bewusstseinslage, dass sie schwierigere Aufgaben vorziehen und die Wahrscheinlichkeit, dabei Erfolg zu haben, höher einschätzen. Schließlich berichten Harmon-Jones und Harmon-Jones (2002, Studie 2) unterschiedliche Effekte der abwägenden und der planenden Bewusstseinslage auf die Verarbeitung von Informationen, die etwas über die Wünschbarkeit gewählter und nicht gewählter Alternativen aussagen. Aus der Dissonanzforschung ist bekannt, dass nach einer Entscheidung für eine von zwei Alternativen die gewählte Alternative deutlich positiver bewertet wird als die nicht gewählte Alternative. Dieser Effekt fällt bei Induktion einer planenden Bewusstseinslage sehr deutlich aus, während er sich bei Induktion einer abwägenden Bewusstseinslage abschwächt.

\section{Klassische Studie zum »lllusionären Optimismus» in der planenden Bewusstseinslage}

In der so genannten »Kontingenzlernaufgabe« (Alloy \& Abramson, 1979) führen Versuchspersonen zahlreiche Durchgänge an einem Apparat durch. Ihre Aufgabe ist es hierbei einzuschätzen, in welchem Ausmaß sie das Aufleuchten eines Lichts (= erwünschtes Ergebnis) bestimmen können. Die Aufgabe ist so gestaltet, dass es den Versuchspersonen frei steht, auszuprobieren, ob das Drücken der Taste oder evtl. das Nichtdrücken der Taste möglicherweise dazu führt, dass das Licht aufleuchtet. Das heißt, dass den Versuchspersonen erklärt wird, dass alternative Handlungen (Drücken der Taste/Nichtdrücken der Taste) zu dem Ergebnis »Aufleuchten des Lichts führen können. Was die Versuchspersonen nicht wissen: Das Aufleuchten des Lichts ist völlig unabhängig davon, ob sie die Taste drücken oder nicht, da es durch einen Zufallsgenerator gesteuert wird.

Der Versuchsleiter kann das tatsächliche Ausmaß an Kontrolle über das Aufleuchten des Lichts variieren, indem er die Häufigkeit, mit der das Licht nach einer der beiden Handlungsalternativen (d. h. dem Drücken bzw. dem Nichtdrücken der Taste) aufleuchtet, durch eine entsprechende Einstellung des
Zufallsgenerators manipuliert. Viele Studien zu dieser »Kontingenzlernaufgabe« (vgl. Alloy \& Abramson, 1988) konnten zeigen, dass, wenn das Aufleuchten des Lichts und somit das erwünschte Ergebnis häufig auftritt (z. B. wenn das Licht in 75\% aller Fälle beim Drücken der Taste und in $75 \%$ aller Fälle beim Nichtdrücken der Taste aufleuchtet), verglichen mit dem Fall, dass das erwünschte Ergebnis seltener auftritt (z. B. wenn das Licht in 25\% aller Fälle des Drückens einer Taste und in 25\% aller Fälle des Nichtdrückens der Taste aufleuchtet) nichtdepressive Personen im Vergleich zu depressiven Personen behaupten, Kontrolle über das Aufleuchten des Lichts zu haben. Das ist erstaunlich, da wie bereits erwähnt in Wirklichkeit das Aufleuchten des Lichts in keiner Weise kontingent mit den jeweiligen Handlungen der Personen ist, sondern durch einen Zufallsgenerator gesteuert wird.

Gollwitzer und Kinney (1989) nahmen an, dass die unrealistische und somit »illusorisch optimistische« Beurteilung der eigenen Kontrollmöglichkeit hinsichtlich des Aufleuchtens des Lichts bei Versuchspersonen in der abwägenden Bewusstseinslage weniger stark ausfallen würde als bei Versuchspersonen in der planenden Bewusstseinslage. Dabei wurde davon ausgegangen, dass Personen, die sich in einer planenden Bewusstseinslage be- 
finden, sich und ihre Fähigkeiten generell viel positiver einschätzen als Personen, die sich in einer abwägenden Bewusstseinslage befinden ( $\downarrow$ Abschn. 12.4). Gollwitzer und Kinney (1989) modifizierten deshalb die beschriebene »Kontingenzlernaufgabe«, indem sie einen zweiten Apparat mit in das Experiment einbauten und die Versuchspersonen baten, 5 Sets von jeweils 20 Durchgängen zu bearbeiten. Ein Durchgang bestand aus dem Drücken bzw. Nichtdrücken der Taste und dem Aufleuchten bzw. Nichtaufleuchten des Lichts. Um die abwägende Bewusstseinslage zu erzeugen, wurde den Versuchspersonen gesagt, dass es ihr Ziel im 1. Teil der Studie sei zu entscheiden, an welchem der beiden zur Verfügung stehenden Apparate sie im 2. Teil der Studie arbeiten möchten. Weiter wurde ihnen gesagt, dass sie zu diesem Zweck ruhig zwischen beiden Apparaten wechseln sollten, bevor sie mit den eigentlichen Durchgängen anfingen. Die Induktion der planenden Bewusstseinslage erfolgte dadurch, dass Versuchspersonen, bevor sie mit dem 1. Set anfingen, sich entscheiden sollten, in welcher Reihenfolge sie bei der Durchführung aller 5 Sets von Durchgängen zwischen beiden Apparaten wechseln wollten. Das heißt, sie sollten selbst entscheiden, wann sie an welchem der beiden Apparate ihre jeweiligen Durchgänge absolvieren wollten, bevor sie mit den Durchgängen anfingen. Nach ihrer Entscheidung wurde ihnen gesagt, dass sie nun versuchen sollten das Licht so häufig wie möglich zum Aufleuchten zu bringen, egal, ob durch das Drücken einer Taste oder durch das Nichtdrücken dieser Taste. Die Versuchspersonen mussten also laut Instruktion selbst »herausfinden«, ob die »Kontrolle« über das Aufleuchten des Lichts durch das Drücken der Taste oder eher durch das Nichtdrücken der Taste zustande kam. Gleichzeitig war es natürlich so, dass der Versuchsleiter wusste, dass das Aufleuchten des Lichts völlig von den Handlungen der Versuchspersonen unabhängig war, sondern nur von einem Zufallsgenerator gesteuert wurde. Außer den beiden Bewusstseinslagen wurde noch jeweils eine von zwei weiteren Bedingungen eingeführt:

- Bedingung »hohe Frequenz des Aufleuchtens«: Das Licht leuchtete entweder in 75\% aller Fälle des Tastendrückens und in $75 \%$ aller Fälle des Nichtdrückens auf oder
- Bedingung »niedrige Frequenz des Aufleuchtens«: Es leuchtete in $25 \%$ aller Fälle des Tastendrückens und in 25\% aller Fälle des Nichtdrückens auf.

Entsprechend boten beide Apparate folgende Bedingungen:

- Bedingung »niedrige Frequenz des Aufleuchtens«: Ein (anscheinend) niedrig »kontingentes « Aufleuchten des Lichts oder

- Bedingung »hohe Frequenz des Aufleuchtens«: Ein (anscheinend) hoch »kontingentes« Aufleuchten des Lichts wurde dargeboten.

War das Aufleuchten des Lichts hoch frequent und somit anscheinend mit dem Handeln der Versuchspersonen hoch »kontingent (Drücken der Taste/Nichtdrücken der Taste), berichteten Versuchspersonen der planenden Bewusstseinslage viel zu hohe (»illusionär optimistische«) Einschätzungen ihrer Kontrollmöglichkeit des Aufleuchtens des Lichts durch das Drücken der Taste bzw. durch das Nichtdrücken der Taste.

Versuchspersonen, die sich in einer abwägenden Bewusstseinslage befanden, schätzten ihre Kontrollmöglichkeit über das Aufleuchten des Lichts deutlich niedriger ein als Versuchspersonen, die sich in einer planenden Bewusstseinslage befanden - sie erkannten offensichtlich, dass ein häufiges Eintreten eines Ereignisses nicht notwendigerweise ein valider Indikator des eigenen Einflusses auf dieses Ereignis ist. Eine abwägende Bewusstseinslage schützt offensichtlich davor, sich in unrealistisch optimistischen Vorstellungen über den eigenen Einfluss auf an sich unkontrollierbare Geschehnisse zu verfangen. War das Aufleuchten des Lichts dagegen niedrig frequent und somit anscheinend auch hinsichtlich des Handelns der Versuchspersonen niedrig kontingent, schätzten Versuchspersonen beider Bewusstseinslagen ihre Kontrolle des Aufleuchtens durch das Drücken der Taste bzw. durch deren Nichtdrücken auf einem mittleren Niveau ein. Dieses Ergebnis zeigt, dass Personen, die sich in einer planenden Bewusstseinslage befinden, sich den von außen gesetzten Grenzen ihres Handelns durchaus anpassen können. Sie behalten nicht einfach unreflektiert ihre Illusion von Kontrolle über ihre Umwelt bei, sondern geben diese angesichts von negativer Rückmeldung (z. B. hohe Quote an »Nicht-Treffern« beim Drücken bzw. Nichtdrücken der Taste) auf.

\section{- Zusammenfassung}

Die planende Bewusstseinslage geht im Vergleich zur abwägenden Bewusstseinslage mit einem gesteigerten Optimismus hinsichtlich des eigenen Einflusses auf erwünschte Handlungsergebnisse sowie dem Vorziehen von schwierigen Aufgaben einher. Weiterhin führt die planende Bewusstseinslage dazu, dass die Wahrscheinlichkeit, erfolgreich zu handeln, höher eingeschätzt wird als in der abwägenden Bewusstseinslage.

\subsubsection{Bewusstseinslagen und Selbstbewertung}

Die abwägende und die planende Bewusstseinslage zeigen auch hinsichtlich der Bewertung der eigenen Person ihre Wirkung. Per-

sonen, bei denen eine abwägende Bewusstseinslage induziert wurde, zeigten eine deutlich niedrigere Selbstwerteinschätzung auf der »Rosenberg-Self-Esteem-Skala« (Rosenberg, 1965) im Vergleich zu Personen nach Induktion einer planenden Bewusstseinslage. Genauso schätzten sich nach Induktion einer planenden Bewusstseinslage studentische Teilnehmer als kreativer, intelligenter und beliebter etc. ein als nach Induktion einer abwägenden Bewusstseinslage (Taylor \& Gollwitzer, 1995). Offensichtlich ist es so, dass durch die Induktion einer planenden Bewusstseinslage der Glaube an sich selbst und an die eigenen Fähigkeiten gestärkt wird. Weiterhin wurde hinsichtlich der von den Versuchspersonen selbst eingeschätzten Anfälligkeit für verschiedene Risiken des menschlichen Lebens beobachtet, dass Versuchspersonen, die sich in einer planenden Bewusstseinslage befinden es als weniger wahrscheinlich ansehen, Opfer verschiedener Unglücksfälle zu werden (wie z. B. eines Flugzeugabsturzes oder an Diabetes zu 
- Tabelle 12.1. Effekte der abwägenden und der planenden Bewusstseinslage auf unterschiedliche Variablen (Taylor \& Gollwitzer, 1995)

\section{Kontrolle Bewusstseinslagen}

Abwägende Planende

Abhängige Variablen

$\begin{array}{llll}\text { Stimmung } & 10.05 & -2.52 & 11.30 \\ \text { Risiko } & 6.05 & 6.00 & 9.71 \\ \text { Selbstwertschätzung } & 41.77 & 37.55 & 41.08 \\ \text { Optimismus } & 30.55 & 27.36 & 29.03\end{array}$

Die Werte wurden den folgenden Skalen entnommen: Stimmung: "Multiple Affect Adjective Checklist" (MAACL, Zuckerman \& Lubin, 1965); Risiko: »Measure of Relative Perceived Risk« (Perloff \& Fetzer, 1986); Selbstwertschätzung: »Rosenberg-self-esteem-Scale« (Rosenberg, 1965); Optimismus: »Life Orientation Test« (LOT, Scheier \& Carver, 1985)

erkranken) als Versuchspersonen, die sich in einer abwägenden Bewusstseinslage befinden. - Tabelle 12.1 zeigt die Ergebnisse dieser Studie.

\subsubsection{Moderatoreffekte in der abwägenden und planenden Bewusstseinslage}

Es hat sich in der Bewusstseinslagenforschung mittlerweile auch gezeigt, dass die Effekte der abwägenden und planenden Bewusstseinslage sowohl durch Unterschiede zwischen Individuen ( $\checkmark$ folgende Übersicht) als auch durch Kontextvariablen moderiert werden (vgl. Gollwitzer, 2003).

Individuelle Unterschiede als Moderatoren von Effekten der abwägenden und der planenden Bewusstseinslage

- Höhe der Leistungsmotivation (nur Erfolgsmotivierte zeigten die bekannten Bewusstseinslageneffekte, Misserfolgsmotivierte dagegen nicht; Puca \& Schmalt, 2001),

- Höhe der sozialen Ängstlichkeit (nur niedrig sozial ängstliche Personen zeigten die beschriebenen Bewusstseinslageneffekte, hoch sozial ängstliche Personen dagegen nicht; Hiemisch, Ehlers \& Westermann, 2002) und

- Positivität des Selbstkonzepts (Bayer \& Gollwitzer, 2005).

- Bewusste Wahrnehmung von Vergleichspersonen (Puca \& Slavova, 2007

Bayer und Gollwitzer (2005) stellten fest, dass Personen mit einem positiven Selbstkonzept in einer abwägenden Bewusstseinslage nach hoch diagnostischen positiven und negativen Informationen hinsichtlich ihres Leistungspotenzials suchen. Befinden sie sich dagegen in einer planenden Bewusstseinslage, suchen sie v. a. nach positiven Informationen unabhängig davon, ob diese hinsichtlich ihres Leistungspotenzials diagnostisch sind oder nicht. Im Gegensatz dazu suchen Personen mit einem negativen Selbstkonzept in der abwägenden Bewusstseinslage v. a. nach positiven Informationen (unabhängig von deren diagnostischem Wert für das eigene Leistungspotenzial) und in der planenden Bewusstseinslage sowohl nach für das eigene Leistungspotenzial hoch diagnostisch positiven als auch nach hoch diagnostisch negativen Informationen.

Als einen weiteren Moderator für die Effekte der abwägenden und der planenden Bewusstseinslage stellte sich der Kontext heraus, in dem die Versuchspersonen sich befanden. Dieser wurde bislang insbesondere im Rahmen von Vorhersagen zur Stabilität der eigenen Partnerschaft untersucht (Gagné \& Lydon, 2001a; Gagné, Lydon \& Bartz, 2003). So stellten Gagné und Lydon (2001a) fest, dass das Abwägen von bereits gefallenen Entscheidungen eine defensive Verarbeitung von Informationen auslösen kann, die die eigene Partnerschaft betreffen. Versuchspersonen, die sich in einer Partnerschaft befanden, wurden gebeten, positive und negative Konsequenzen eines Anliegens, das die Partnerschaft betraf oder die Konsequenzen eines Anliegens abzuwägen, das nichts mit ihrer Partnerschaft bzw. nichts mit Partnerschaften im Allgemeinen zu tun hatte sowie die Wahrscheinlichkeit des Eintretens dieser Konsequenzen abzuwägen (zur Induktion von Bewusstseinslagen - Abschn. 12.4): Versuchspersonen beurteilten ihren Partner positiver, wenn sie vorher die Konsequenzen eines Anliegens gegeneinander abgewogen hatten, das mit ihrer Partnerschaft in Bezug stand, als wenn sie die Konsequenzen eines für die Partnerschaft irrelevanten Anliegens gegeneinander abgewogen hatten. Interessanterweise war die Beurteilung des Partners sogar nach der Induktion der abwägenden Bewusstseinslage anhand eines partnerschaftsrelevanten Anliegens noch positiver als nach Induktion einer planenden Bewusstseinslage. Gagné und Lydon (2001a) zogen daraus den Schluss, dass das Abwägen der eigenen Partnerschaft als deren Bedrohung wahrgenommen worden war. Das resultierte wiederum in einer positiven Beurteilung des eigenen Partners, um diese Bedrohung abzuwehren. In einer weiteren Studie (Gagné \& Lydon, 2001b) hielten sie deshalb anhand einer Reihe von Fragen das "Commitment« fest, das die Versuchspersonen ihrer Partnerschaft gegenüber empfanden. Hierbei zeigte sich, dass sich nur Versuchspersonen mit einem hohen Commitment hinsichtlich ihrer Partnerschaft gegen die Bedrohung ihrer Beziehung durch das Abwägen eines Beziehungsproblems schützten, indem sie ihren Partner besonders positiv bewerteten. Versuchspersonen mit einem niedrigen Commitment gegenüber ihrer Partnerschaft taten dies nicht. Insofern stellt auch das Commitment gegenüber der eigenen Partnerschaft einen wichtigen Moderator der Effekte der abwägenden und der planenden Bewusstseinslage bei partnerschaftsrelevanten Themen dar. Puca und Slavova (2007) untersuchten soziale Vergleichsprozesse in Abhängigkeit von der abwägenden und der planenden Bewusstseinslage. Sie stellten hierbei fest, dass Versuchsteilnehmer in einer planenden Bewusstseinslage nur dann eine stärkere Abwertung eines potenziellen Konkurrenten zeigten als Versuchsteilnehmer in einer abwägenden Bewusstseinslage, wenn sie der Meinung waren, nicht wirklich gegen ihn antreten zu müssen. Wurde den Versuchsteilnehmern dagegen mitgeteilt, dass sie sich in einem Spiel mit dem Konkurrenten tatsächlich messen müssen (und somit 
direktes Feedback hinsichtlich ihrer eigenen Leistungen im Vergleich zu seiner Leistung erhalten würden), verschwanden die Unterschiede in der Bewertung des Konkurrenten zwischen Versuchsteilnehmern der beiden Bewusstseinslagen.

\section{Zusammenfassung \\ Als Moderatoren für die Effekte der abwägenden und der pla- nenden Bewusstseinslage haben sich das Selbstkonzept, der Kontext von Beziehungen und der tatsächliche Vergleich mit konkurrierenden Personen herausgestellt. Das Selbstkonzept bewirkt in Interaktion mit der jeweiligen Bewusstseinslage unterschiedliche Effekte auf die Verarbeitung von diagnos- tischen Informationen unterschiedlicher Valenz. Die Auswir- kung der Bewusstseinslage auf die Einschätzung des eigenen Partners hängen vom jeweiligen Kontext und Commitment auf die Partnerschaft ab. Die Beurteilung der eigenen Leis- tungsfähigkeit im Vergleich zu anderen Personen hängt von der jeweiligen Bewusstseinslage und davon ab, inwiefern wirklich eine direkte Konfrontation mit diesen Personen statt- finden wird oder nicht.}

\subsubsection{Bewusstseinslagen und Zielrealisierung}

Ausgangspunkt bei den Studien zur Auswirkung der beiden Bewusstseinslagen auf die konkrete Realisierung von Zielen war die Hypothese, dass die planende Bewusstseinslage für die Realisierung von Zielen förderlicher sein sollte als die abwägende Bewusstseinslage, da sich hier sowohl die Informationsverarbeitung als auch die Selbsteinschätzung voll und ganz auf die Realisierung des beabsichtigten Anliegens ausrichten ( $\triangleright$ Abschn. 12.4).

Ein guter Prädiktor für die tatsächliche Realisierung von Zielen im Alltag ist die Persistenz des zielfördernden Verhaltens, d. h. die Ausdauer, mit der ein Handelnder versucht, schwierigen Herausforderungen zu begegnen und diese zu meistern. Einige Autoren haben aus diesem Grund untersucht, inwiefern sich die abwägende und die planende Bewusstseinslagen auf die Persistenz des Zielstrebens auswirken. So fanden Pösl (1994) sowie Brandstätter und Frank (2002) heraus, dass die planende Bewusstseinslage Personen dahingehend beeinflusst, länger an der Durchführung schwieriger Aufgaben festzuhalten. Die Versuchspersonen von Brandstätter und Frank (2002, Studie 1) versuchten sich länger daran, ein schwieriges Puzzle zu lösen, wenn vorher eine planende Bewusstseinslage induziert worden war im Vergleich zu Versuchspersonen nach Induktion einer abwägenden Bewusstseinslage.

Ein differenziertes Bild liefern die Befunde Pösls (1994): Versuchspersonen, die sich in einer planenden Bewusstseinslage befanden, zeigten nur in Situationen eine Persistenz zielfördernden Verhaltens, in denen ein Verhaltenskonflikt zwischen Wünschbarkeit und Realisierbarkeit des angestrebten Ziels (Anliegens) schwelte. War dagegen sowohl die wahrgenommene Durchführbarkeit zielfördernden Handelns als auch die Wünschbarkeit des Ziels hoch oder beides niedrig, wurde die Persistenz des Zielstrebens nicht mehr durch die jeweils induzierte Bewusstseinslage beeinflusst. Nur wenn die wahrgenommene Durchführbarkeit zielfördernden Handelns und die Wünschbarkeit des Ziels in unterschiedliche Richtungen ging (entweder war das eine hoch und das andere niedrig oder umgekehrt), behielten Versuchspersonen in der planenden Bewusstseinslage länger die für die Erreichung des Ziels erforderlichen Verhaltensweisen bei als Versuchspersonen der abwägenden Bewusstseinslage. Es bleibt ferner festzuhalten, dass die durch die planende Bewusstseinslage ausgelöste Persistenz zielfördernden Verhaltens nicht rigide ist. Brandstätter und Frank (2002, Studie 2) konnten zeigen, dass es in einer planenden Bewusstseinslage schneller zur Ablösung von dem verfolgten Ziel kommt, sobald eine Aufgabe als unlösbar erkannt wird oder die Persistenz von Verhalten, das eigentlich zielfördernd sein sollte, sich als unvorteilhaft herausstellt als in einer abwägenden Bewusstseinslage. Es scheint also so zu sein, dass die Persistenz, die mit der planenden Bewusstseinslage assoziiert ist, flexibel und anpassungsfähig ist.

Hinsichtlich der effektiveren Zielrealisierung in der planenden Bewusstseinslage im Vergleich zu abwägenden Bewusstseinslage berichten Armor und Taylor (2003) von einer Studie, in der die Induktion einer planenden Bewusstseinslage zu besseren Leistungen führte als die Induktion einer abwägenden Bewusstseinslage. Zusätzlich stellten diese beiden Autoren fest, dass dieser Effekt durch die kognitiven Merkmale der planenden Bewusstseinslage, wie z. B. ein verstärktes Selbstwirksamkeitserleben, optimistische Ergebniserwartungen etc., vermittelt worden war ( Abschn. 12.4.4).

(D)

Die planende Bewusstseinslage unterstützt die Realisierung von Zielen stärker als die abwägende Bewusstseinslage.

Alle bisher gefundenen Effekte der abwägenden und der planenden Bewusstseinslage sind in - Tabelle 12.2 zusammengefasst.

\subsubsection{Abschließende Diskussion: Bewusstseinslagen und die Selbstregulation des Zielstrebens}

Es stellt sich hinsichtlich der Selbstregulation des Zielstrebens die Frage, inwiefern Menschen sich intentional in eine bestimmte Bewusstseinslage begeben können, um ihre Chancen zu erhöhen, ein bestimmtes Ziel erfolgreich zu verfolgen oder sich umgekehrt endgültig von diesem Ziel zu lösen, falls dieses sich als unrealistisch oder wenig wünschenswert erweisen sollte. Für die Unterstützung des Zielstrebens erwies sich die planende Bewusstseinslage als besonders effektiv ( Abschn. 12.4.6). In der bereits erwähnten Studie von Armor und Taylor (2003) führten mit der planenden Bewusstseinslage assoziierte optimistische Erwartungen hinsichtlich der Realisierung eines angestrebten Ziels zu effektiverer Selbstregulation hinsichtlich der tatsächlichen Zielrealisierung und besseren Ergebnissen in einer Leistungsaufgabe als die mit der abwägenden Bewusstseinslage assoziierten weniger optimistischen Erwartungen hinsichtlich der Realisierung eines Ziels. Genauso konnten Pösl (1994) und Brandstätter und Frank (2002, Studien 1 und 2) zeigen, dass die Induktion einer planenden Bewusstseinslage dazu führt, dass angestrebte Ziele eher erreicht werden, was v. a. an der größeren Persistenz des Zielstrebens, die durch diese Bewusstseinslage ausgelöst wird, zu liegen scheint. 
- Tabelle 12.2. Effekte der abwägenden und der planenden Bewusstseinslage

\begin{tabular}{|c|c|c|}
\hline & Abwägende Bewusstseinslage & Planende Bewusstseinslage \\
\hline Auswirkungen auf das Selbstkonzept & $\begin{array}{l}\text { Niedrige Selbstwerteinschätzung } \\
\text { Auf positiven Eigenschaften (z. B. Intelligenz, } \\
\text { Kreativität) schätzt man sich etwas besser ein } \\
\text { als vergleichbare andere Personen } \\
\text { Eigene Vulnerabilität gegenüber kontrollier- } \\
\text { baren und nicht kontrollierbaren Risiken wird } \\
\text { hoch eingeschätzt }\end{array}$ & $\begin{array}{l}\text { Hohe Selbstwerteinschätzung } \\
\text { Auf positiven Eigenschaften (z. B. Intelligenz, } \\
\text { Kreativität) schätzt man sich deutlich besser ein } \\
\text { als vergleichbare andere Personen } \\
\text { Eigene Vulnerabilität gegenüber kontrollier- } \\
\text { baren und nicht kontrollierbaren Risiken wird } \\
\text { niedrig eingeschätzt }\end{array}$ \\
\hline \multirow[t]{2}{*}{$\begin{array}{l}\text { Auswirkungen auf die Informations- } \\
\text { verarbeitung }\end{array}$} & Offenheit für Informationen aller Art & $\begin{array}{l}\text { Bevorzugte Verarbeitung von Informationen, } \\
\text { welche die Realisierung eines Vorhabens } \\
\text { unterstützen }\end{array}$ \\
\hline & $\begin{array}{l}\text { Gedanken drehen sich generell um } \\
\text { »abwägendes« Verhalten } \\
\text { Gute Erinnerung an abwägendes Verhalten } \\
\text { von anderen Personen } \\
\text { Breit gestreute Aufmerksamkeit }\end{array}$ & $\begin{array}{l}\text { Gedanken drehen sich generell um } \\
\text { »planendes« Verhalten } \\
\text { Gute Erinnerung an planendes Verhalten } \\
\text { von anderen Personen } \\
\text { Zentral fokussierte Aufmerksamkeit }\end{array}$ \\
\hline $\begin{array}{l}\text { Auswirkungen auf Optimismus/ } \\
\text { Pessimismus }\end{array}$ & $\begin{array}{l}\text { Gering ausgeprägtes Gefühl von Kontrolle } \\
\text { über unkontrollierbare Ereignisse } \\
\text { Realismus hinsichtlich zukünftiger eigener } \\
\text { Leistungen } \\
\text { Vergleichsweise negative Beurteilung der } \\
\text { eigenen Partnerschaft/des Partners }\end{array}$ & $\begin{array}{l}\text { Illusionäres Gefühl von Kontrolle über } \\
\text { unkontrollierbare Ereignisse } \\
\text { Optimismus hinsichtlich zukünftiger eigener } \\
\text { Leistungen } \\
\text { Vergleichsweise positive Beurteilung der } \\
\text { eigenen Partnerschaft/des Partners }\end{array}$ \\
\hline Auswirkungen auf die Motivation & $\begin{array}{l}\text { Verringerte Ausdauer bei der Umsetzung } \\
\text { eines Vorhabens }\end{array}$ & $\begin{array}{l}\text { Erhöhte Ausdauer bei der Umsetzung eines } \\
\text { Vorhabens }\end{array}$ \\
\hline
\end{tabular}

Unbedingt sollte allerdings bei der Diskussion über den $\mathrm{Zu}$ sammenhang zwischen planender Bewusstseinslage und der Realisierung von Zielen beachtet werden, dass ihr positiver Einfluss v. a. für Aufgaben gilt, die sofort nach der Induktion dieser Bewusstseinslage durchgeführt werden. Je weiter die Aufgabendurchführung zeitlich von der Induktion der planenden Bewusstseinslage entfernt ist, desto weniger kommt ihr positiver Einfluss auf die Zielrealisierung zum Tragen, wie Gagnè und Lydon (2001a) und Puca (2001) feststellen konnten.

\section{Zusammenfassung}

Grundsätzlich gilt, dass die Induktion einer Bewusstseinslage natürlich nicht zu einer permanenten Beeinflussung der Informationsverarbeitung und der Selbsteinschätzung führt; die Wirkungen beider Bewusstseinslagen kommen nach einer gewissen Zeit nicht mehr zum Tragen.

\subsection{Unterschiedliche Arten von Handlungs- intentionen: Zielintentionen (Absichten) und Durchführungs- intentionen (Vorsätze)}

Das Setzen von Zielen wird in der wissenschaftlichen Psychologie, aber auch in naiven Alltagstheorien häufig als eine gute Strategie betrachtet, eigene Wünsche zu realisieren oder auch Anforderungen gerecht zu werden. Im Gegensatz dazu konnte in zahlreichen Studien nachgewiesen werden, dass die tatsächliche
Realisierung dieser Ziele oft auf sich warten lässt: Auch hoch motivierte Personen tun sich häufig schwer, ein bestimmtes Vorhaben wirklich in die Tat umzusetzen. Manchmal liegt es daran, dass sie einfach zögern, hinsichtlich der Realisierung ihrer Ziele auch wirklich etwas zu unternehmen und deshalb keine zielfördernden Handlungen initiieren. Manchmal streben sie aber auch $\mathrm{zu}$ viele, häufig miteinander konkurrierende Ziele an, von denen viele langfristige Projekte darstellen, die deshalb auflange Zeiträume hinweg immer wieder Anstrengungen erforderlich machen. Bisweilen stehen der Erreichung von Zielen aber auch situative Hindernisse entgegen. Das ist dann der Fall, wenn ein Handelnder eine günstige Gelegenheit zur Umsetzung von Zielen in die Realität nicht erkennt, weil er gerade abgelenkt ist und sich seine Aufmerksamkeit z. B. auf intensive emotionale Erfahrungen richtet.

( Im Gegensatz zur Vorstellung, dass das Setzen von Zielen für die Realisierung erwünschter Anliegen ausreichend ist, zeigt eine Vielzahl von Studien, dass die tatsächliche Realisierung von Zielen häufig nicht stattfindet.

Gollwitzer (1993, 1999) analysierte basierend auf Überlegungen von Narziß Ach $(1905,1910,1935)$ und Kurt Lewin (1926b) das Phänomen, dass Ziele häufig nicht realisiert werden als Selbstregulationsproblem. Diese Analyse kommt zu dem Schluss, dass Ziele häufig erst dann realisiert werden können, wenn die Selbstregulationsstrategie des Planens eingesetzt wird. Unter Planen wird die im Voraus gedanklich stattfindende Realisierung von Zielen verstanden. Aufgrund dieser Überlegungen werden zwei Arten von Intentionen unterschieden: 
Zielintentionen (Absichten, "goal intentions«) und

- Vorsätze (Durchführungsintentionen, »implementation intentions $\lll)$.

Das Konzept der »Absicht« bzw. »Zielintention« ähnelt Lewins (1926b) Vorstellung von Intentionen.

\section{$>$ Definition}

Absichten oder Zielintentionen definieren entsprechend erwünschte Endzustände, die bisher noch nicht erreicht worden sind. Somit handelt es sich bei Absichten oder Zielintentionen um »Ziele« im landläufigen Sinne.

Beispiele für Zielintentionen sind: »Ich will ein guter Psychologe sein!« oder »Ich will mich einer bestimmten Person gegenüber freundlich verhalten!«

\section{$>$ Definition}

Vorsätze stehen im Dienste von Zielintentionen und sind Pläne, die deren Realisierung unterstützen. Um die Umsetzung einer Zielintention in die Wirklichkeit zu fördern, definiert ein Handelnder in einem Vorsatz eine Situation oder Bedingung, bei deren Eintreten ein bestimmtes Verhalten gezeigt wird. Dieses Verhalten wiederum wird so festgelegt, dass es bei Eintreten der im Vorsatz definierten Situation oder Bedingung die Erreichung der Zielintention unterstützt $(\checkmark$ Beispiel). Vorsätze besitzen deshalb das Format »Wenn $\mathrm{X}$ eintritt, dann will ich Verhalten $Y$ ausführen!« und werden deshalb auch häufig als Wenn-Dann-Pläne bezeichnet.

\section{Beispiel}

Ein Vorsatz für eine Person, die sich gerne gesund ernähren möchte (in diesem Fall könnte die dem Vorsatz übergeordnete Zielintention lauten »/ch will mich gesund ernähren!«), wäre z. B.: »Wenn ich im Restaurant um meine Bestellung gebeten werde, dann wähle ich einen Salat!« In der Vorsatzforschung wird davon ausgegangen, dass, nachdem dieser Vorsatz gefasst worden ist, bei Eintreten der Situation »Essensbestellung « direkt das Verhalten »wähle ich einen Salat« ausgelöst wird.
Häufig wird die Frage gestellt, worin eigentlich der Unterschied zwischen »habits « und Vorsätzen besteht, weil beide dazu führen, dass ein mit einer bestimmten Situation oder einem bestimmten Reiz verbundenes Verhalten automatisch ausgeführt wird, sobald diese Situation eintritt bzw. der entsprechende Reiz auftaucht.

( Vorsätze unterscheiden sich von »habits« darin, dass für ihre Etablierung nur ein einziger Willensakt notwendig ist, bei dem ganz bewusst eine enge Verbindung zwischen einer bestimmten Situation bzw. einem bestimmten Reiz und einem zielfördernden Verhalten generiert wird. Bis ein »habit« sich im offenen Verhalten niederschlägt sind dagegen viele konsistente Wiederholungen einer bestimmten Verhaltensweise in derselben Situation erforderlich (vgl. Fitts \& Posner, 1967; Newell \& Rosenbloom, 1981).

\subsubsection{Wie funktionieren Vorsätze?}

In der Vorsatzforschung wurde durch zahlreiche Studien untersucht, auf welche psychologischen Prozesse die Wirkung von Vorsätzen zurückgeführt werden kann (s. Meta-Analyse von Gollwitzer \& Sheeran, 2006). Im Mittelpunkt standen hierbei Überlegungen zur chronischen Aktivierung der im Vorsatz spezifizierten Situation sowie der Realisierung des Vorsatzes aufgrund automatischer Prozesse.

\section{Die spezifizierte Situation: Chronische Aktivierung}

Da das Fassen eines Vorsatzes die bewusste Auswahl einer bestimmten Situation oder eines bestimmten Reizes als »WennTeil« des Vorsatzes beinhaltet, wird angenommen, dass die mentale Repräsentation dieser Situation hoch aktiviert und dadurch kognitiv leicht zugänglich ist (Gollwitzer, 1999). Diese erhöhte kognitive Zugänglichkeit erleichtert es einem Handelnden, die Aufmerksamkeit auf die im Vorsatz spezifizierte Situation zu richten, selbst wenn er mit anderen Dingen beschäftigt ist, und die Situation auch dann zu bemerken, wenn diese im Kontext verborgen erscheint (Parks-Stamm, Gollwitzer \& Oettingen, 2007). Gleichzeitig führt die hohe Aktivierung der im Vorsatz spezifizierten Situation zu einem besseren Wiedererinnern dieser

\section{Studie}

\section{Klassische Studie zur kognitiven Zugänglichkeit der im Vorsatz spezifizierten Situation}

Durch Einsatz einer dichotischen Höraufgabe konnte gezeigt werden, dass Wörter, welche eine in einem Vorsatz spezifizierte Situation beschrieben, anderweitig ausgerichtete Aufmerksamkeit effektiv durchbrachen. Man präsentierte Versuchspersonen mithilfe eines Kopfhörers simultan Wörter auf beide Ohren. Sie sollten nun die auf dem einen Ohr dargebotenen Wörter »beschatten«, d. h. laut nachsprechen, sobald sie diese gehört hatten. Dadurch wurde die Aufmerksamkeit stark auf dieses Ohr fokussiert. Gleichzeitig sollten die auf dem anderen Ohr präsentierten Wörter ignoriert werden. Es zeigte sich in diesem Experiment, dass wenn auf das »zu ignorierende Ohr« Wörter präsentiert wurden, die mit der im Vorsatz spezifizierten günstigen
Situation assoziiert waren, die eigentlich auf das andere Ohr fokussierte Aufmerksamkeit auf sich zogen. Die Versuchspersonen reagierten in diesem Fall nämlich in ihrer »Beschattungsaufgabe« langsamer, als wenn auf dem zu ignorierenden Ohr Wörter präsentiert worden waren, die keinerlei Bezug zum Vorsatz hatten. Eine Gruppe von Versuchspersonen, die sich nur eine Zielintention gesetzt hatte, zeigte diesen Effekt ebenso wenig wie eine Gruppe von Versuchspersonen, die sich hinsichtlich der durchzuführenden Aufgabe gar keine Intention gesetzt hatten.

Dieses Ergebnis weist darauf hin, dass die im Vorsatz spezifizierte Situation nicht so leicht der Aufmerksamkeit eines Handelnden entgeht, auch wenn er stark mit anderen Dingen beschäftigt ist. 
Situation, wenn es um die Frage geht, wann und wo das zielfördernde Verhalten durchgeführt werden soll. Außerdem wird die im Vorsatz spezifizierte Situation auch schneller wahrgenommen als Situationen, die nicht im Vorsatz spezifiziert worden sind. Im Folgenden wird eine klassische Studie dazu beschrieben.

Ein weiterer Beleg für die Annahme einer hohen kognitiven Zugänglichkeit der im Vorsatz spezifizierten Situation sind die Ergebnisse einer Studie zur Entdeckung eingebetteter Figuren im Gottschaldt-Test (Gottschaldt, 1926). Bei diesem Test gilt es, kleinere »a-Figuren «, die inmitten von größeren »b-Figuren « versteckt sind, zu entdecken. Spezifizierten Versuchspersonen die "a-Figuren « im »Wenn-Teil« eines Vorsatzes, entdeckten sie diese häufiger als Versuchspersonen, die sich für die Entdeckung dieser Figuren nur eine Zielintention gesetzt hatten (Steller, 1992).

In einer Studie, bei der eine Erinnerungsaufgabe gestellt wurde, konnte der Nachweis erbracht werden, dass Versuchspersonen, die sich mithilfe eines Vorsatzes darauf festgelegt hatten, wann sie bestimmte Spiele im Rahmen verschiedener vorgefertigter Optionen spielen wollten, in einer unerwarteten Gedächtnisabfrage sowohl sofort als auch $48 \mathrm{~h}$ später viel besser ihre jeweils gewählten Optionen nennen konnten als Versuchspersonen, die sich nur eine Zielintention gesetzt hatten (Achtziger, Bayer \& Gollwitzer, 2009, Studie 2).

Aarts, Dijksterhuis und Midden (1999) wiesen die erhöhte kognitive Zugänglichkeit der im Vorsatz spezifizierten Situation mithilfe einer lexikalischen Entscheidungsaufgabe nach. In dieser reagierten Versuchspersonen, die sich einen Vorsatz gefasst hatten, schneller auf Wörter, welche in diesem Vorsatz als Situation spezifiziert worden waren als Versuchspersonen, die sich diesbezüglich nur eine Zielintention gesetzt hatten (zur kognitiven $\mathrm{Zu}$ gänglichkeit vgl. auch Webb \& Sheeran, 2007, 2008).

(C) Die chronische Aktivierung der im Vorsatz spezifizierten Situation manifestiert sich also in deren hoher kognitiven Zugänglichkeit. Diese schlägt sich wiederum in einem schnellen Erkennen der Situation, ihrer Fähigkeit, die Aufmerksamkeit auf sich zu ziehen und ihrem guten Wiedererinnern nieder.

\section{Initiierung der im Vorsatz vorgenommenen Handlung}

Wie bereits angesprochen, erfolgt die Realisierung eines Vorsatzes automatisch, nachdem er bewusst durch einen einmaligen Willensakt gefasst wurde. Dadurch kann ein Handelnder strategisch zwischen bewusster und mit dem Verbrauch an kognitiven Ressourcen verbundener Kontrolle zielfördernden Verhaltens und der automatischen Kontrolle dieses Verhaltens durch die aktuelle Situation hin- und herschalten. Gollwitzer et al. (z. B. Gollwitzer \& Schaal, 1998; Gollwitzer, Fujita, \& Oettingen, 2004) sprechen in diesem Zusammenhang von »strategischer « Automatizität. Die Annahme einer automatischen Realisierung von Vorsätzen bedeutet, dass diese bei Eintreffen der in ihnen spezifizierten Situation sofort, effizient und ohne bewusstes Wollen in die Tat umgesetzt werden. Ein Handelnder, der sich einen Vorsatz gefasst hat, muss also nicht erst bewusst und unter Aufwendung kognitiver Ressourcen mühevoll dafür sorgen, dass die im Vorsatz geplante zielfördernde Verhaltensweise bei Eintreten der spezifizierten Situation auch wirklich in die Tat umgesetzt wird.

Das bringt verschiedene Vorteile mit sich, die Vorsätze im Vergleich zu Zielintentionen effektiver werden lassen. Beispiels-

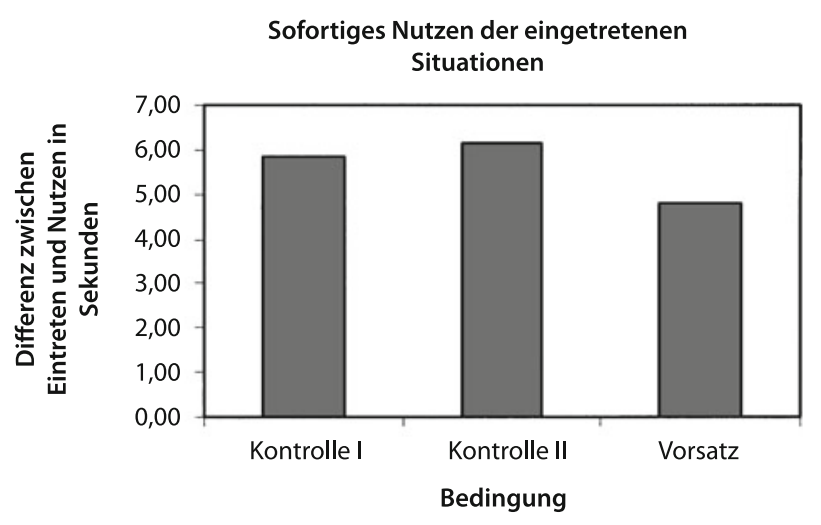

- Abb. 12.2. Reaktionszeiten in einem Doppelaufgaben-Experiment mit und ohne Vorsatzbildung (Brandstätter, Lengfelder \& Gollwitzer, 2001)

weise konnte gezeigt werden, dass selbst bei hoher Ablenkung die im Vorsatz definierte Situation sofort genutzt wird. Für die Effizienz vorsatzgesteuerter automatischer Handlungsinitiierung sprechen so genannte »Doppelaufgaben-Experimente« (Brandstätter, Lengfelder \& Gollwitzer, 2001). Bei diesen Experimenten müssen Versuchspersonen zwei Aufgaben gleichzeitig durchführen. Schmälert sich dadurch die Leistung in der einen Aufgabe, dann wird das so interpretiert, dass die Durchführung der anderen Aufgaben nur unter Verbrauch von kognitiven Ressourcen zustande kommen kann. Eine Reihe von Studien konnten mithilfe solcher Doppelaufgaben-Experimente belegen, dass die Realisierung eines Vorsatzes keine kognitiven Ressourcen erfordert. So konnte in zwei Studien von Brandstätter et al. (2001, Studie 3 und 4) der Nachweis erbracht werden, dass Studierende bei Erledigung einer Reaktionszeitaufgabe und gleichzeitiger kognitiver Belastung durch eine andere Aufgabe schneller reagierten, wenn sie sich einen Vorsatz gefasst hatten, der auf die schnelle Reaktion auf bestimmte dargebotene Reize abzielte. Studierende, die sich nur die Zielintention gesetzt hatten, möglichst schnell zu reagieren, gelang dies bei gleichzeitiger kognitiver Belastung nicht. In - Abb. 12.2 werden die Ergebnisse dieser Studie gezeigt.

Untersuchungen an klinischen Stichproben. In weiteren Studien gelang es Brandstätter et al. (2001) zu zeigen, dass auch Patienten mit schwerwiegenden Handlungskontrollproblemen, die durch chronische kognitive Belastung zustande kamen, ebenfalls von Vorsätzen profitieren. In diesem Sinne gelang es z. B. Drogenabhängigen auf Entzug durch das Fassen eines Vorsatzes Verhaltensweisen, die ihre Wiedereingliederung in ein normales Leben ermöglichte, rechtzeitig durchzuführen. Mithilfe eines Vorsatzes waren sie in der Lage, ihre Vita in einem vorgegebenen Zeitraum fertig zu stellen, um sich damit auf Stellenangebote zu bewerben. Ohne Vorsatz verpassten sie es, die Vita rechtzeitig abzugeben. Ihre chronische kognitive Belastung, die auf den Entzug zurückführen ist, wirkte sich dann nicht hemmend auf zielförderndes Verhalten aus, wenn dieses in einem Vorsatz festgelegt worden war.

Lengfelder und Gollwitzer (2001) führten zur Überprüfung der Hypothese der automatischen Realisierung von Vorsätzen Studien mit Patienten, die an einer Schädigung des Frontalhirns litten, durch. Ein besonders auffälliges Problem dieser Patienten ist das 
Defizit, automatisierte Handlungen bzw. Gewohnheiten im Sinne von »habits« willentlich kontrollieren zu können. Für diese Patienten führt z. B. der Anblick einer Schere dazu, nach dieser zu greifen und damit das Schneiden anzufangen, ohne dass sie diese Handlung bewusst und willentlich unterbrechen können, auch wenn sie das stark beabsichtigen. Ein Reiz, der mit der Durchführung einer bestimmten Handlung assoziiert ist, löst diese also bei Patienten nach Frontalhirnschädigung unwillkürlich und unvermeidlich aus. Lengfelder und Gollwitzer (2001) machten sich dieses Phänomen zunutze und baten solche Patienten an einer Go/ NoGo-Aufgabe teilzunehmen. Bei dieser Aufgabenform muss eine rasche Reaktion auf $\mathrm{z}$. B. zwei von fünf unterschiedlichen auf dem Bildschirm präsentierten Reizen (z. B. visuelle Muster) gezeigt werden (im Sinne einer selektiven Aufmerksamkeitsleistung). Sollten der Annahme von Lengfelder und Gollwitzer (2001) zufolge Vorsätze tatsächlich auf automatischen Prozessen basieren, dann müsste v. a. diese Patientengruppe in der Go/NoGo-Aufgabe schnellere Reaktionszeiten auf die im Vorsatz als Situation spezifizierten Reize zeigen als eine Kontrollgruppe von gesunden Personen. Die Vorhersagen bestätigten sich: Die Patienten zeigten signifikant schnellere Reaktionszeiten als die gesunden Personen.

(D) Dieses Ergebnis deutet darauf hin, dass für die Realisierung von Vorsätzen keine durch den Frontallappen gesteuerten exekutiven Funktionen erforderlich sind, was letztlich ein Indikator für ihre automatische Realisierung ist.

Dieses Ergebnis wurde auch durch Studien von Achtziger, Michalski und Gollwitzer (in Vorbereitung) und Gawrilow und Gollwitzer (2008) unterstützt. Achtziger et al. (in Vorbereitung) konnten mithilfe eines Verfahrens, das die zentrale Exekutive des Arbeitsgedächtnisses blockiert (vgl. Baddeley, 1996), nachweisen, dass Versuchspersonen, die sich einen Vorsatz zur Unterstützung der Verarbeitung stereotypinkonsistenter Informationen über eine $\mathrm{zu}$ beurteilende Person gefasst hatten, dies genauso gut konnten wie Versuchspersonen, bei denen die Funktionen der zentralen Exekutive nicht blockiert worden waren. Versuchspersonen, die sich keinen Vorsatz gebildet hatten, waren dagegen nicht in der Lage bei gleichzeitiger Blockade der zentralen Exekutive die stereotypinkonsistente Information zu verarbeiten und stereotypisierten entsprechend die zu beurteilende Person. Die Blockade der zentralen Exekutive belastet stark den Frontallappen (Baddeley, 1996) und ermöglicht entsprechend primär automatische Prozesse. Die Wirkung des Vorsatzes trotz dieser Blockade indiziert somit erneut seine Unabhängigkeit von Prozessen, die kognitive Ressourcen verbrauchen.

Gawrilow und Gollwitzer (2008) demonstrierten erfolgreich die Wirkung von Vorsätzen bei einer Gruppe von Kindern, die an einer Aufmerksamkeitsdefizitstörung (ADHS) litten. Kinder mit ADHS sind dafür bekannt, dass sie große Defizite bei der Durchführung von exekutiven Funktionen und somit bei Prozessen aufweisen, die kognitive Ressourcen erfordern. Deshalb haben es diese Kinder sehr schwer, auf Stoppsignale verlässlich und zügig zu reagieren. Vor Durchführung einer Variante der so genannten Stopp-Aufgabe (vgl. Logan, Schachar \& Tannock, 1997) wurden Kinder mit ADHS gebeten, sich einen Vorsatz zu fassen, der darauf ausgerichtet war, auf einen bestimmten Stimulus eine adäquate Stoppreaktion zu zeigen. Mithilfe dieses Vorsatzes gelang es den Kindern mit ADHS tatsächlich, die gewünschte Verhaltenshemmung genauso gut zu implementieren wie einer Kontrollgruppe von gesunden Kindern. Es konnte somit ein erneuter Nachweis erbracht werden, dass die Wirkung von Vorsätzen auf automatischen Prozessen beruht und eben nicht auf Prozessen,

\section{Studie zur Handlungsinitiierung ohne bewusste Kontrolle}

Um den Nachweis zu erbringen, dass die Handlungsinitiierung gesteuert durch Vorsätze keiner bewussten Kontrolle bedarf, sobald die spezifizierte Situation eintritt, führten Bayer, Achtziger, Gollwitzer und Moskowitz (2009) zwei Studien durch. Bei diesen wurde die im Vorsatz spezifizierte Situation subliminal (d. h. unterhalb der Wahrnehmungsschwelle) präsentiert. Exemplarisch wird an dieser Stelle Studie 1 vorgestellt:

Es wurde untersucht, inwiefern Versuchspersonen in der Lage sind, ihr Ziel, sich gegen eine unfreundliche Versuchsleiterin zu verteidigen, mithilfe eines Vorsatzes realisieren zu können. Die eine Hälfte der Versuchspersonen setzte sich zu diesem Zweck die Zielintention, der Versuchsleiterin die Meinung zu sagen und sie auf ihr unfreundliches Verhalten hinzuweisen. Die restlichen Versuchspersonen fassten sich zusätzlich zu dieser Zielintention den Vorsatz, der Versuchsleiterin die Meinung zu sagen, sobald sie diese zu Gesicht bekommen würden. Danach wurde allen Versuchspersonen mithilfe eines Tachistoskops subliminal (mit einer Darbietungszeit von weniger als $10 \mathrm{~ms}$ ) entweder das Gesicht der unfreundlichen Versuchsleiterin oder das Gesicht einer neutralen, unbekannten Person als »Prime« präsentiert. Primes sind Reize, die dazu dienen, damit assoziierte kognitive Inhalte zu aktivieren. Diese kognitiven Inhalte werden nach den Primes dargeboten und man hält in der Regel den Effekt des Primes auf die nachfolgenden Inhalte anhand von Reaktionszeiten fest. Jeder Präsentation eines »Primes « folgte in engem Zeitabstand die Darbietung von Wörtern, die entweder mit Unfreundlichkeit assoziiert waren (z. B. offensiv, aggressiv, eingebildet) oder die damit nicht assoziiert waren. Die Versuchspersonen wurden gebeten, alle diese Wörter so schnell wie möglich nachzusprechen, während ein Computer die Zeit von der Präsentation der Wörter bis zu deren Nachsprechen erfasste. Versuchspersonen, die sich den Vorsatz gefasst hatten, der unfreundlichen Versuchsleiterin die Meinung zu sagen, sobald sie diese antreffen würden, reagierten schneller auf die mit Unfreundlichkeit assoziierten Wörter, wenn vorher subliminal das Gesicht der Versuchsleiterin präsentiert worden war als Versuchspersonen, die sich nur die entsprechende Zielintention gesetzt hatten.

Das Ergebnis macht nochmals deutlich, dass die Initiierung des im Vorsatz vorgenommenen zielfördernden Verhaltens automatisch erfolgt. Das bedeutet, dass dieses Verhalten unverzüglich, effizient und ohne bewusstes Wollen ausgelöst wird, sobald die im Vorsatz spezifizierte Situation eintritt. 
die auf zentral exekutive Funktionen und somit auf kognitive Ressourcen zurückgreifen.

Die unmittelbare, sofortige Auslösung des im Vorsatz spezifizierten Verhaltens bei Eintreten der in ihm spezifizierten Situation konnte durch Gollwitzer und Brandstätter (1997, Studie 3) demonstriert werden. Versuchspersonen hatten sich einen Vorsatz gefasst, der Situationen spezifizierte, bei deren Eintreten sie auf eine Reihe von rassistischen Bemerkungen, die von einem Vertrauten der Versuchsleiterin geäußert wurden, sofort Gegenargumente nennen sollten, während eine andere Gruppe sich diesbezüglich nur eine Zielintention gesetzt hatte. Versuchspersonen der Vorsatzgruppe reagierten wie erwartet auf die rassistischen Bemerkungen schneller mit Gegenargumenten als Versuchspersonen der Zielintentionsgruppe. Im Folgenden wird eine Studie dargestellt, die den Nachweis erbrachte, dass die Handlungsiniitierung durch Vorsätze keiner bewussten Kontrolle bedarf.

Die Rolle von Commitment bei der Realisierung von Vorsätzen. Manchmal wird die Frage gestellt, ob die Wirkung von Vorsätzen nicht auch oder womöglich sogar rein auf die Erhöhung des Commitments auf die Zielintention zurückzuführen ist, die potenziell durch das Fassen eines Vorsatzes zustande kommen könnte. Führt also das Fassen eines Vorsatzes möglicherweise zur Erhöhung des Commitments, die übergeordnete Zielintention zu realisieren, und ist deshalb die Annahme einer durch ihn ausgelösten automatischen Initiierung zielfördernden Verhaltens und weiterer kognitiver Prozesse überflüssig? Eine Reihe von Studien erbrachte den Nachweis, dass dies nicht der Fall ist. So konnten Brandstätter et al. (2001, Studie 1) nachweisen, dass der positive Effekt des Vorsatzes auf das rechtzeitige Abfassen einer Vita vom generellen Commitment der Patienten, eine Vita zu schreiben, unabhängig war: Patienten der Vorsatzgruppe zeigten nach dem Fassen des Vorsatzes kein höheres Commitment auf die Zielintention als Patienten der Zielintentionsgruppe. Die Beobachtung, dass der Vorsatz nicht zu einer Commitmenterhöhung hinsichtlich der respektiven Zielintention führt, wurde in zahlreichen Studien repliziert: Beispielsweise erhöhten im Bereich der Krankheitsprävention Vorsätze genauso wenig das Commitment auf die Zielintention (z. B. Orbell, Hodgkins \& Sheeran, 1997) wie im Bereich der sozialen Eindrucksbildung (Seifert, 2001, Studie 1 und 2; Achtziger, 2003, Studie 1 und 2) sowie in Wettkampfsituationen des Tennissports (Achtziger, Gollwitzer \& Sheeran, 2008, Studie 2).

Alle bisher entdeckten Prozesse, auf denen die Wirkung von Vorsätzen basiert, sind in der folgenden Übersicht zusammengefasst.

\section{Prozesse der Vorsatzwirkung}

- Chronische Aktivierung der im Vorsatz spezifizierten Situation (z. B. besseres Gedächtnis, spontane Aufmerksamkeitszuwendung, bessere Entdeckungsleistung),

- Automatizität der Realisierung zielfördernden Verhaltens (z. B. geringer Verbrauch an kognitiven Ressourcen),

- Automatische Initiierung der im Vorsatz vorgenommenen Handlung (z. B. unverzüglich, effizient und ohne bewusstes Wollen).

\subsubsection{Vorsätze und die Initiierung erwünschter Zielhandlungen}

Da Vorsätze das Entdecken, die Aufmerksamkeitszuwendung und das Wiedererinnern von günstigen Situationen zur Durchführung zielfördernden Verhaltens unterstützen und obendrein eine automatische Handlungsinitiierung begünstigen, sollten Personen, die ihre Zielintentionen mit Vorsätzen ausstatten, höhere Erfolgsraten bei der Realisierung dieser Zielintentionen aufweisen als Personen, die das nicht tun. Diese Annahme wird durch zahlreiche Studien aus sehr verschiedenen Handlungsfeldern bestätigt.

\section{Vorsatzeffekte bei Zielhandlungen im Leistungs- und Gesundheitsbereich}

Häufig werden in der Vorsatzforschung Zielintentionen als Studienobjekte ausgewählt, die aus den bereits erwähnten Gründen wie z. B. Ablenkungen von innen und außen oder auch nur deshalb, weil die Ausführung der Zielhandlung unangenehm oder schmerzhaft ist, schwierig zu realisieren sind. So untersuchten Gollwitzer und Brandstätter (1997) die Realisierung einer Zielintention, die in den Weihnachtsferien von Studierenden in der Tat geschehen sollte. Den Versuchspersonen wurde die Aufgabe gestellt, während der Weihnachtsferien einen Bericht über den Heiligabend zu schreiben. Wie erwartet taten das Studierende, die sich einen entsprechenden Vorsatz gefasst hatten, signifikant häufiger als Studierende, die sich diesbezüglich nur eine Zielintention gesetzt hatten.

Orbell, Hodginks und Sheeran (1997) erbrachten den Nachweis, dass das regelmäßige Abtasten der Brust zur Brustkrebsprävention häufiger durchgeführt wird, wenn Frauen sich diesbezüglich einen Vorsatz gefasst hatten. Dasselbe galt für Studien, welche die Teilnahme an freiwilligen Krebsvorsorgeuntersuchungen (Sheeran \& Orbell, 2000), die Wiederaufnahme von körperlichen Aktivitäten nach Hüftgelenksoperationen (Orbell \& Sheeran, 2000) und die Durchführung von sportlichen Übungen (Milne, Orbell \& Sheeran, 2002) untersuchten. Weiterhin konnten positive Vorsatzeffekte bei Aufgaben gefunden werden, die leicht vergessen werden, wie z. B. die reguläre Einnahme von Vitamintabletten (Sheeran \& Orbell, 1999) oder das Signieren der einzelnen Arbeitsblätter eines Intelligenztests (Chasteen, Park \& Schwarz, 2001). Achtziger et al. (2008, Studie 1) konnten zeigen, dass Personen mit Hilfe von Vorsätzen den Konsum von Fastfood einschränken konnten.

\section{Bedeutsame Moderatoren der Vorsatzwirkung}

Die Stärke der Vorsatzwirkung hängt von verschiedenen Moderatoren ab. So ließ sich in einigen Studien (z. B. Gollwitzer \& Brandstätter, 1997, Studie 1) beobachten, dass Vorsatzeffekte umso offensichtlicher werden, je schwieriger es ist, ein zielförderndes Verhalten zu initiieren. Zu dieser Überlegung passen die Befunde der erwähnten Studie mit Patienten, die an einer Frontalhirnschädigung litten (Lengfelder \& Gollwitzer, 2001, Studie 2; - Abschn. 12.5.1). Diese haben typischerweise große Probleme mit der Durchführung von Handlungen, weil exekutive Funktionen bzw. kognitive Ressourcen nur noch eingeschränkt zur Verfügung stehen. Tatsächlich waren die Leistungen von Patienten nach Frontalhirnschädigung, die sich einen Vorsatz für die 
Durchführung einer Reaktionszeitaufgabe gesetzt hatten, besser als die Leistungen einer studentischen Stichprobe mit demselben Vorsatz. Geht man davon aus, dass die Reaktionszeitaufgabe für die Patienten schwerer durchzuführen ist als für die gesunden Studierenden, dann zeigt sich auch hier, dass gerade schwierige Zielhandlungen von der Vorsatzbildung profitieren.

Ein weiterer Moderator für die Vorsatzwirkung scheint das Commitment auf die dem Vorsatz zugrunde liegende Zielintention zu sein. Orbell et al. (1997) berichten in diesem Zusammenhang, dass die positiven Effekte eines Vorsatzes auf die Durchführung von Maßnahmen zur Brustkrebsfrüherkennung sich nur bei den Frauen zeigten, welche im Sinne einer Zielintention stark beabsichtigten, eine Selbstuntersuchung der Brust durchzuführen. Übereinstimmend mit dieser Beobachtung fanden auch Achtziger et al. (2009, Studie 2), dass positive Effekte eines Vorsatzes auf das Wiedererinnern der im Vorsatz spezifizierten Situation nur dann auftraten, wenn die dem Vorsatz übergeordnete Zielintention noch in die Tat umgesetzt werden musste. War sie bereits anderweitig realisiert worden, zeigte sich kein Vorsatzeffekt auf die Gedächtnisleistung. Weiterhin zeigten Sheeran, Webb und Gollwitzer (2005, Studie 1), dass die Zielintention, sich auf das anstehende Examen vorzubereiten, umso mehr von Vorsätzen profitierte, je mehr Lernaufwand sie bedeutete. Zusätzlich zur Notwendigkeit eines starken Commitments auf die Zielintention ist auch das Commitment auf den jeweils gefassten Vorsatz erforderlich. In der genannten Gedächtnisstudie wurde die Stärke des Commitments auf den Vorsatz dadurch variiert, dass den Versuchspersonen entweder nach Durchführung einer Reihe von Persönlichkeitstests gesagt wurde, dass sie zu dem Personenkreis gehören würden, der davon profitieren würde rigide an einem Vorsatz festzuhalten (Bedingung: »hohes Commitment auf den Vorsatz«) oder dass sie zu dem Personenkreis gehören würde, der gewöhnlich davon profitiert, flexibel zu bleiben (Bedingung: »niedriges Commitment auf den Vorsatz«). Versuchspersonen, bei denen auf diese Weise niedriges Commitment auf den Vorsatz induziert worden war, zeigten deutlich schwächere Vorsatzeffekte.

Sheeran et al. (2005, Studie 2) entdeckten, dass Vorsatzeffekte nur dann auftreten, wenn sich die dem Vorsatz zugrunde liegende Zielintention in einem aktivierten Zustand befindet. Der Vorsatz, in einem Intelligenztest nach der Bearbeitung eines Items sofort und ohne Pause zum nächsten zu wechseln, hatte nur dann einen Effekt auf die Geschwindigkeit der Aufgabenbearbeitung, wenn die Zielintention, möglichst schnell zu arbeiten, aktiviert worden war. Auch Cohen, Bayer, Jaudas und Gollwitzer (2008, Studie 1) zeigten mithilfe eines Wechselaufgabenparadigmas von Rogers und Monsell (1995), dass die Wirkung von Vorsätzen von der Aktivierung der übergeordneten Zielintention abhängig ist.

Schließlich dürfte gelten, dass auch die Stärke der Verknüpfung zwischen dem »Wenn-Teil« eines Vorsatzes und seinem »Dann-Teil« Vorsatzeffekte positiv beeinflusst. Wenn ein Handelnder viel Zeit und Konzentration dafür aufwendet, den Vorsatz im Langzeitgedächtnis zu enkodieren oder wenn er ihn innerlich immer wiederholt, sollte sich eine stärkere Verbindung zwischen den beiden Vorsatzteilen ausbilden, die wiederum stärkere Vorsatzeffekte generieren sollten als eine schwache Verbindung zwischen beiden Teilen. Dies konnten mittlerweile Studien von Webb und Sheeran $(2007,2008)$ bestätigen und darüber hinaus wurde von anderen Autoren gezeigt, dass diese starke Verbin- dung über die Zeit hinweg recht stabil ist und sich nicht sofort wieder abbaut (Papies, Aarts \& de Vries, 2009).

\section{Zusammenfassung}

Als bedeutsame Moderatoren der Vorsatzwirkung haben sich die Schwierigkeit der Initiierung zielfördernden Verhaltens, das Commitment auf die Zielintention und auf den Vorsatz sowie die Aktivierung der Zielintention erwiesen.

\subsection{Vorsätze und die Kontrolle unerwünschten Verhaltens}

Bisher hat sich die Vorsatzforschung stark darauf konzentriert, wie Vorsätze dazu dienen können, erwünschtes zielförderndes Verhalten auch wirklich in die Tat umzusetzen, um auf diese Weise Zielintentionen zu realisieren. Hierbei beschäftigte sie sich häufig mit dem Problem, wie zielförderndes Verhalten überhaupt initiiert werden kann. Allerdings ist bekannt, dass das alleinige Initiieren zielfördernden Verhaltens oft nicht ausreicht, um eine Zielintention auch wirklich zu realisieren: Nach der Initiierung zielfördernden Verhaltens muss der Prozess des Zielstrebens weiter aufrechterhalten werden. In diesem Sinne muss ein Handelnder das Zielstreben davor schützen, aufgrund attraktiver Ablenkungen wieder beendet zu werden oder konfligierenden schlechten Gewohnheiten zum Opfer zu fallen. Wie dies durch Vorsätze verhindert werden kann, wird nachfolgend geschildert.

Unerwünschte zielbehindernde Reaktionen können durch verschiedene Vorsatztypen kontrolliert werden. Wenn sich z. B. ein Handelnder gegenüber einem Freund freundlich verhalten möchte, obwohl dieser eine unverschämte Bitte an ihn richtet, kann er seine Ärgerreaktion vermeiden, indem er die Zielintention »Ich will freundlich bleiben! « mit einem der folgenden drei Suppressionsvorsätze ergänzt:

1. Suppressionsvorsatz: »Und wenn mein Freund mit einer unverschämten Bitte an mich herantritt, dann werde ich nicht unfreundlich reagieren!«

Dieser Vorsatz verfolgt die Strategie, unerwünschtes Verhalten dadurch zu kontrollieren, dass er dieses unterdrückt, indem er die kritische Situation im »Wenn-Teil« und das Nichtzeigen der unerwünschten Reaktion im »Dann-Teil« spezifiziert. Alternativ dazu wäre ein Vorsatz denkbar, der auf die Initiierung einer erwünschten Reaktion fokussiert:

2. Suppressionsvorsatz: »Und wenn mein Freund mit einer unverschämten Bitte an mich herantritt, dann werde ich freundlich reagieren!«

Bei diesem Vorsatz wird erneut die kritische Situation im »Wenn-Teil« spezifiziert und im »Dann-Teil« das vom Handelnden erwünschte Verhalten, das durch die spontan auftretende, aber nicht beabsichtigte Ärgerreaktion bedroht wird.

3. Suppressionsvorsatz: »Und wenn mein Freund mit einer unverschämten Bitte an mich herantritt, dann werde ich diese ignorieren! «

Diese Vorsatzvariante spezifiziert erneut die kritische Situation im »Wenn-Teil«, während der »Dann-Teil« eine Nichtreaktion nahe legt. 


\section{Vorsatzgesteuerte Hemmung von Ablenkungen}

Gollwitzer und Schaal (1998) ließen Studenten eine Reihe von Rechenaufgaben lösen, die auf dem Bildschirm eines Computers präsentiert wurden. Während sie dies taten, wurden auf einem Fernsehbildschirm, der oberhalb des Computerbildschirms befestigt worden war, beliebte Werbevideos in unregelmäßigen Zeitabständen eingespielt. Es zeigte sich in dieser Studie, dass ein Vorsatz, das Lösen der Rechenaufgaben vor der Ablenkung durch die Werbevideos zu schützen effektiver war als die Zielintention »/ch will mich nicht ablenken lassen!«. Allerdings konnte in dieser Studie auch beobachtet werden, dass ein Vorsatz, der so formuliert wurde, dass er Ablenkungen hemmt (»Wenn eine Ablenkung auftaucht, dann werde ich sie ignorieren!«) bessere Ergebnisse erzielte als ein Vorsatz, der auf eine Leistungssteigerung in den Rechenaufgaben fokussierte
(»Wenn eine Ablenkung auftaucht, dann werde ich mich auf das Lösen der Mathematikaufgaben konzentrieren!«). Der Vorsatz, der die Ablenkung hemmen sollte, führte - unabhängig von der Motivation der Versuchspersonen, die langweiligen Rechenaufgaben zu lösen - dazu, sich von den Werbevideos nicht ablenken zu lassen. Der Vorsatz, der darauf fokussierte, trotz Ablenkung die Leistung beim Lösen der Rechenaufgaben hochzuhalten, konnte nur bei niedriger Motivation, die langweiligen Rechenaufgaben zu lösen, diese Zielintention unterstützen. War diese Motivation dagegen hoch, konnte mithilfe des Vorsatzes die Ablenkung durch die Werbevideos nicht verhindert werden - es wurden schlechte Leistungen beim Lösen der Rechenaufgaben erbracht. Dieser Befund legt nahe, dass dieser 2. Vorsatz unter Ablenkungsbedingungen Übermotivation erzeugt hatte und dadurch die Leistung verschlechterte.
Gollwitzer und Mitarbeiter haben eine Vielzahl von Studien durchgeführt, die diese drei Arten von Vorsätzen zur Kontrolle unerwünschter Reaktionen benutzt haben. Diese Studien bezogen sich primär auf die Kontrolle nicht erwünschter spontaner Reaktionen auf Ablenkungen sowie der Kontrolle von Stereotypen und Vorurteilen gegenüber sozialen Gruppen.

\subsubsection{Suppressionsvorsätze}

Wenn das Streben nach einer Zielintention durch Ablenkungen bedroht wird, sollten Vorsätze gefasst werden, die in der Lage sind, aufmerksamkeitsablenkende Reize zu ignorieren. Zur Veranschaulichung dient die folgende Studie.

Suppression von Vorurteilen. Neben der vorsatzgesteuerten Inhibition von Ablenkungen bei der Durchführung von Aufgaben wurde auch die Unterdrückung von unerwünschten Effekten in der sozialen Eindrucksbildung untersucht. Allgemein nehmen Eindrucksbildungsmodelle (z. B. Brewer, 1988; Devine, 1989) an, dass der Einfluss sozialer Stereotype und Vorurteile auf die Beurteilung fremder Personen nur durch Prozesse möglich ist, welche Aufmerksamkeit, kognitive Ressourcen und bewusste Anstrengung erfordern. In diesem Sinne wurde in der Stereotypie- und Vorurteilsforschung bis vor kurzem davon ausgegangen, dass zwar die Anwendung von Stereotypen und Vorurteilen intentional verhindert werden kann, nicht jedoch deren Aktivierung (vgl. Brewer, 1988; Devine, 1989). Denn die Aktivierung von Stereotypen und Vorurteilen gilt als unvermeidlicher und automatischer Prozess, während ihre Anwendung durch aufwändige Prozesse als kontrollierbar gilt. Ausgehend von den bereits erwähnten Studien zur automatischen Wirkungsweise von Vorsätzen ( $\triangleright$ oben) führten wir eine Reihe von Experimenten durch, die prüfen sollten, ob es mithilfe von Vorsätzen sogar möglich ist, die automatische Aktivierung von Stereotypen und von Vorurteilen zu beeinflussen und nicht nur deren Anwendung. Die Annahme lautete, dass ein automatischer Prozess wie die Aktivierung eines Stereotyps durch andere automatische Prozesse, wie sie z. B. durch einen Vorsatz ausgelöst werden, blockiert werden können.
Mithilfe verschiedener Priming-Prozeduren wurde gezeigt, dass bei Versuchspersonen nach expliziter Vorsatzbildung (»Wenn ich einen alten Mann sehe, dann sage ich mir: Jetzt keine Vorurteile!«) die Aktivierung des Stereotyps »alter Mann« ausblieb, während sie in einer Gruppe von Versuchspersonen, die sich nur eine Zielintention (»Ich will fair urteilen!«) gesetzt hatten und bei einer Kontrollgruppe, die sich nur einen Eindruck von den präsentierten Personen bilden sollten, nach wie vor beobachtet wurde (Gollwitzer, Achtziger \& Schaal, in Vorbereitung). Dieselben Ergebnisse traten in einer Studie auf, in der männliche Versuchspersonen das Stereotyp »Frau « und auch in Studien, in denen Versuchspersonen beiderlei Geschlechts die Stereotype »Obdachloser« oder »Fußballfans « hemmen sollten.

Andere Studien untersuchten, inwiefern Vorsätze auch in der Lage sind, die Anwendung von Stereotypen zu unterbinden. In diesem Sinne überprüfte Seifert (2001, Studie 1), inwiefern die Benachteiligung weiblicher Bewerber auf Arbeitsplätze in technischen Bereichen durch Vorsätze aufgehoben werden kann. Seifert (2001, Studie 1) legte zu diesem Zweck Informatikstudenten Bewerbungsunterlagen und ein Anforderungsprofil für die Stelle eines Informatikers vor. Die Hälfte der Bewerbungsunterlagen war mit dem Namen einer Frau, die andere Hälfte mit dem Namen eines Mannes versehen. In einer Vorstudie wurden den Bewerbungsunterlagen ausschließlich männliche Namen zugeordnet und es zeigte sich, dass sie dann als gleichwertig (im Sinne einer gleichen Eignung für die ausgeschriebene Stelle) beurteilt wurden. Wurden nach dem Zufallsprinzip jedoch männliche und weibliche Namen auf die Bewerbungsunterlagen verteilt, entschieden sich die Informatikstudenten deutlich häufiger für die Einstellung von männlichen Bewerbern und benachteiligten dadurch die weiblichen Bewerber. Nur einer Gruppe von Informatikstudenten, die sich den Vorsatz gefasst hatte "Wenn ich die Eignung eines Bewerbers oder einer Bewerberin beurteilen muss, ignoriere ich deren Geschlecht! « gelang es, diesen Bias zu überwinden. In der Stereotypieforschung gilt es als gut belegt, dass Menschen unter kognitiver Belastung nicht in der Lage sind, stereotypinkonsistente Informationen über eine fremde Person zu verarbeiten (vgl. Macrae, Hewstone \& Griffiths, 1993). Bei diesen Informationen handelt es sich um solche, die Vertretern 
bestimmter sozialer Kategorien grundsätzlich nicht zugeschrieben werden, wie z. B. die Eigenschaft »tolerant« der Gruppe der "Machos« im Allgemeinen nicht zugerechnet wird. Wenn es jedoch gelingt, stereotypinkonsistente Informationen zu verarbeiten, gelangt man zu einem nicht stereotypen Eindruck. Achtziger et al. (in Vorbereitung) replizierten den Effekt einer mangelhaften Verarbeitung stereotypinkonsistenter Informationen unter kognitiver Belastung und konnten gleichzeitig nachweisen, dass ein Vorsatz es jedoch ermöglicht, auch unter kognitiver Belastung die stereotypinkonsistente Information zu verarbeiten und dadurch zu einem fairen Urteil zu kommen.

Suppression emotionaler Reaktionen. Neben der Regulation unerwünschter Reaktionen wie Ablenkung und unfaire Beurteilung fremder Personen, konnte in der Vorsatzforschung auch gezeigt werden, dass unerwünschte Reaktionen wie starke negative Emotionen kontrolliert werden können. So berichten Schweiger Gallo, Keil, McCulloch, Rockstroh und Gollwitzer (2009) von einer Studie zur vorsatzgesteuerten Kontrolle von Ekel. Den weiblichen Versuchspersonen wurden emotionsauslösende Bilder des »International Affective Picture System « (IAPS; CSEA, 1999) präsentiert. Ein Teil dieser Bilder, nämlich Fotografien von verletzten und verstümmelten Personen, aktiviert die Emotion »Ekel«. Mithilfe eines Vorsatzes gelang es den Versuchspersonen ihren Ekel zu unterdrücken, während das mit der Zielintention alleine nicht erreicht wer- den konnte. Das zeigte sich auch an den dazugehörigen neuronalen Reaktionen im Gehirn während der Präsentation der Bilder.

\section{Zusammenfassung}

Suppressionsvorsätze haben sich bei der Unterdrückung spontaner Aufmerksamkeitsreaktionen, bei der Kontrolle stereotyper und vorurteilshafter Reaktionen, sowie bei der Kontrolle reflexhaft negativer emotionaler Reaktionen als wirksam erwiesen.

\subsubsection{Blockieren nachteiliger Selbstzustände durch Planen der gewollten Handlung}

In der in Abschn. 12.6.1 präsentierten Forschung wurde im »Wenn-Teil« des jeweiligen Vorsatzes eine kritische Situation definiert, die mit einem »Dann-Teil« verbunden worden war, der dazu diente, unerwünschte Reaktionen zu unterbinden. Vorsätze können einen Handelnden jedoch auch durch eine völlig andere Vorgehensweise vor unerwünschten Reaktionen schützen. Anstatt Vorsätze auf die antizipierten Hindernisse und die Unterdrückung unerwünschter Reaktionen darauf auszurichten, können sie auch so formuliert werden, dass sie darauf ausgerichtet sind, das aktuelle Streben nach Realisierung einer Zielintention
Studie zur Blockierung negativer Selbstzustände

Eine der Studien zur Überwindung negativer Selbstzustände (Bayer et al., 2010, Studie 3) basiert auf der Theorie der symbolischen Selbstergänzung (Wicklund \& Gollwitzer, 1982) und überprüft, inwiefern die negativen Effekte des Unvollständigkeitserlebens hinsichtlich einer erwünschten Identität auf die Sensibilität gegenüber anderen Personen (vgl. Gollwitzer \& Wicklund, 1985) durch das Fassen eines Vorsatzes kontrolliert werden können. Bei den Versuchspersonen handelte es sich um Jurastudenten, die dazu hoch motiviert waren, gute Juristen zu werden. Ihnen wurde als Coverstory mitgeteilt, dass es das Ziel dieser Studie sei, die Effekte von Zielen auf das Kennenlernen von anderen Leuten zu analysieren. Deshalb würden sie jetzt eine andere Person kennen lernen und sollten versuchen, sich während des Kennenlerngesprächs in die Perspektive des unbekannten Interaktionspartners zu versetzen. Die Hälfte der Versuchspersonen wurde dazu aufgefordert, sich zusätzlich zu dem Ziel, die Perspektive des unbekannten Interaktionspartners einzunehmen, folgenden Vorsatz zu fassen: »Und wenn mein Gesprächspartner eine Vorliebe für ein bestimmtes Thema äußert, dann werde ich meine Konversation genau auf dieses Thema abstimmen!«. Danach füllten sie entweder einen Fragebogen über das Thema aus, wie sie an ihr Jura-Studium herangehen möchten (Bedingung »kein Unvollständigkeitserleben«) oder sie beantworteten zusätzlich zu diesem Fragebogen weitere drei Fragen, die so formuliert waren, dass sie den Versuchspersonen ihre derzeitigen Unzulänglichkeiten im Hinblick auf ihre juristischen Fähigkeiten aufwiesen (z. B. »Haben Sie bereits Erfahrungen als Richter oder als Staatsanwalt ge- sammelt?«). Dieser zweite Fragebogen diente dazu, ein Unvollständigkeitserleben zu erzeugen.

Schließlich wurden alle Versuchspersonen darüber informiert, dass ihre Konversationspartnerin in der Kennenlernsituation Nadja heißen wird und dass Nadja bereits ihre Vorliebe für bestimmte Gesprächsthemen geäußert hätte. Daraufhin erhielten sie ein Blatt Papier, auf dem die Präferenzen von Nadja hinsichtlich der Gesprächsthemen niedergeschrieben waren. Aus diesen Präferenzen wurde ersichtlich, dass Nadja nicht über Jura, sondern lieber über ihren letzten Urlaub und beliebte Kinofilme reden wollte. Um festzustellen, inwiefern Unvollkommenheitsgefühle hinsichtlich einer erwünschten Identität die Bereitschaft erhöhen, trotz anderer Vorlieben von Nadja das Thema »Jura« als Gesprächsstoff zu wählen, um dadurch einen Selbstergänzungseffekt zu erzeugen, mussten alle Versuchspersonen schließlich ihre eigenen Gesprächswünsche angeben. In der Kontrollbedingung zeigten die Versuchspersonen einen deutlichen Selbstergänzungseffekt:Versuchspersonen mit Unvollständigkeitserleben wollten häufiger über Jura sprechen als Versuchspersonen ohne Unvollständigkeitserleben, obwohl Nadja deutliches Desinteresse an diesem Thema zum Ausdruck gebracht hatte. Dieser Effekt trat bei Versuchspersonen, die sich einen Vorsatz gefasst hatten, jedoch nicht auf - sowohl Versuchspersonen ohne als auch solche mit Unvollständigkeitserleben zeigten keine Tendenz, das Thema »Jura« in der Kennenlernsituation anzusprechen.

Diese Ergebnisse machen deutlich, dass Vorsätze die negativen Effekte des Selbstzustands »Unvollständigkeitserleben« auf das Zielhandeln (die Perspektive einer anderen Person zu übernehmen) blockieren können. 
zu stabilisieren. Wenn man z. B. müde und erschöpft ist, so kann eine fachliche Diskussion über widersprüchliche Meinungen schnell zu einer hitzigen Diskussion werden, obwohl alle Beteiligten dies nicht wünschen. Wurde jedoch schon im Voraus geplant, wie man mit konträren Meinungen konstruktiv umgehen will, sollten die Selbstzustände Müdigkeit und Erschöpfung keinen negativen Einfluss auf den Ablauf der Diskussion haben. Diese Annahmen wurden in einer Reihe von Studien überprüft. Im Folgenden wird eine davon exemplarisch dargestellt.

\section{Vorsatzbildung und Selbstregulationskapazität}

Die Theorie der verminderten Selbstregulationskapazität (»egodepletion theory«; Baumeister, 2000; Muraven, Tice \& Baumeister, 1998) postuliert, dass die Durchführung einer Aufgabe, die sehr viel Selbstregulationskapazität erfordert, die Leistung in einer zweiten Aufgabe, die ebenfalls Selbstregulationskapazität erfordert, beeinträchtigt. Es interessierte Bayer, Gollwitzer \& Achtziger (2010, Studie 1 und 2), inwiefern man diesen Effekt durch einen Vorsatz verhindern kann. Um die Selbstregulationskapazität zu vermindern, schauten sich die Versuchspersonen zunächst einen lustigen Film an und erhielten entweder die Instruktion, ihren Emotionen hierbei freien Lauf zu lassen oder gar keine Emotionen zu zeigen. Nachfolgend sollten sie schwierige Anagramme lösen, wobei sich alle Versuchspersonen für diese Aufgabe die Zielintention setzten, so viele Anagramme wie möglich zu lösen. Die Hälfte der Versuchspersonen fasste sich zusätzlich zu dieser Zielintention den Vorsatz »Wenn ich ein Anagramm gelöst habe, dann löse ich sofort das nächste Anagramm!« Versuchspersonen, die sich nur die Zielintention gesetzt hatten, zeigten den klassischen Effekt einer verminderten Selbstregulationskapazität: Versuchspersonen, die während des Films ihre Emotionen unterdrücken mussten, zeigten schlechtere Leistungen bei der Anagrammaufgabe als Versuchspersonen, die ihren Emotionen freien Lauf lassen durften. Dieser Effekt zeigte sich nicht bei Versuchspersonen, welche sich zusätzlich zur Zielintention den Vorsatz gefasst hatten.

Die Kompensation von verminderter Selbstregulationskapazität durch das Fassen eines Vorsatzes konnten auch Webb und Sheeran (2003, Studie 2) demonstrieren. Eine verminderte Selbstregulationskapazität wurde dadurch hergestellt, dass die Versuchspersonen sich auf ihr »schwächeres« Bein stellen und gleichzeitig von 1.000 in Siebenerschritten rückwärts zählen sollten. Versuchspersonen in der Kontrollbedingung standen ganz normal auf zwei Beinen und zählten in Fünferschritten vorwärts bis 1.000. Dann erhielten alle Versuchspersonen die Zielintention, während einer Stroop-Aufgabe so schnell wie möglich die Farbe zu benennen, in der dargebotene Wörter geschrieben worden waren. Versuchspersonen der Vorsatzbedingung fassten zusätzlich den Vorsatz »Sobald ich ein Wort sehe, dann ignoriere ich dessen Bedeutung und nenne die Farbe, in der es abgebildet ist! «. Bei Versuchspersonen der Vorsatzbedingung ließ sich keine verminderte Selbstregulationskapazität beobachten: Sie sprachen die Farbe der Wörter genauso schnell aus wie Versuchspersonen, bei denen die Selbstregulationskapazität nicht vermindert worden war. Dagegen zeigten alle Versuchspersonen, die sich nur die Zielintention gesetzt hatten, nach einer Verminderung der Selbstregulationskapazität deutlich schlechtere Farbbenennungsleistungen in der StroopAufgabe als ohne Verminderung der Selbstregulationskapazität.

\section{Zusammenfassung}

Mithilfe von Vorsätzen wurden sowohl negative Effekte von Unvollständigkeitserleben hinsichtlich einer erwünschten Identität, als auch negative Effekte einer verminderten Selbstregulationskapazität überwunden.

\subsubsection{Blockieren nachteiliger kontextueller Einflüsse durch Planen der gewollten Handlung}

Personen können sich die erwünschten Ergebnisse ihrer Handlungen als Gewinne oder Verluste vorstellen (Kahneman \& Tversky, 1979). Forschungsergebnisse auf dem Gebiet der Konfliktlösung haben gezeigt, dass kognitive Prozesse, die aufgrund eines so genannten »Verlustframings« oder eines »Gewinnframings « entstehen, einen starken Einfluss auf Verhandlungsergebnisse haben (De Dreu, Carnevale, Emans \& van de Vliert, 1994). Verlustframing führt häufig zu vergleichsweise unfairen Vertragsabschlüssen und anderen negativen Effekten. Aus diesem Grund stellte sich die Frage, inwiefern die negativen Effekte des Verlustframings erfolgreich durch prosoziale Ziele, wie z. B. das Ziel, eine faire oder integrative Lösung zu finden, überwunden werden können, wenn diese durch entsprechende Vorsätze unterstützt werden. Diese Hypothese wurde in zwei Experimenten von Trötschel und Gollwitzer (2007) überprüft. Exemplarisch wird Experiment $1 \mathrm{im}$ Folgenden vorgestellt.

\section{Vorsatzbildung und Leistungsrückmeldung}

Die Realisierung von Zielen kann auch durch ungünstige Leistungsrückmeldungsbedingungen negativ beeinflusst werden. Ein Beispiel ist hier das so genannte Social-loafing-Phänomen, das häufig an Arbeitsplätzen beobachtet wird, wo keine individuellen, sondern nur kollektive Leistungsrückmeldungen gegeben werden (vgl. Latané, Williams \& Harkins, 1979; Karau \& Williams, 1993). Unter »social loafing « wird die Tatsache verstanden, dass Personen dann geringere Leistungen erbringen, wenn sie in einem Team arbeiten als wenn sie alleine sind. So tritt in Teams, in denen nicht nachvollzogen werden kann, wer welchen Beitrag bei der Erfüllung einer Aufgabe erbracht hat, »social loafing « auf, d. h. man strengt sich weniger an, weil andere sich auch an der Arbeit beteiligen. Gollwitzer und Bayer (2000, Studie 4) prüften, ob »social loafing « mithilfe von Vorsätzen in den Griff zu bekommen ist. Versuchspersonen erhielten die Instruktion, so viele Nutzungsmöglichkeiten eines einfachen Messers wie möglich zu nennen. Diese Aufgabe galt es unter einer von zwei Bedingungen durchzuführen:

- Bedingung »kollektive Leistungsrückmeldung«:

Es wurde den Versuchspersonen mitgeteilt, dass außer ihnen noch 7 Personen dieselbe Aufgabe durchführen würden und dass der Versuchsleiter am Ende nicht in der Lage wäre zu bestimmen, wer wie viele Beiträge zur Gesamtleistung dieses Teams geleistet hätte.

- Bedingung »individuelle Leistungsrückmeldung«: In der Kontrollbedingung zum Social-loafing-Phänomen wurde den Versuchspersonen dagegen erzählt, dass es im Nachhinein durchaus möglich wäre festzustellen, wie viel jeder Einzelne zur Gesamtleistung dieses Teams beigetragen hätte. 


\section{Überwindung von Verlustframingeffekten mithilfe von Vorsätzen}

Jeweils zwei Versuchspersonen wurde die Rolle des Staatsoberhaupts eines von zwei konkurrierenden Ländern zugeteilt. Die beiden Versuchspersonen sollten nun über die Verteilung einer umstrittenen Insel verhandeln. Die Insel bestand aus 25 Regionen, von denen jede eine von vier unterschiedlichen Landschaften repräsentierte: Berge, Kornfelder, Weideland und Wälder. Eine der beiden Versuchspersonen wurde auf folgende Weise einem Verlustframing ausgesetzt:

- Verlustframing-Bedingung:

Man gab ihr eine Tabelle, welche die vier unterschiedlichen Regionen auflistete und jeweils mit einer negativen Punktezahl den Verlust signalisierte, der entstehen würde, wenn diese Region der anderen Versuchsperson abgegeben werden würde. Die andere Versuchsperson innerhalb jedes Verhandlungspaares erhielt ein Gewinnframing.

- Gewinnframing-Bedingung:

Die Tabelle, die die unterschiedlichen Regionen auflistete, zeigte diesmal positive Punktzahlen, welche bei der Inbesitznahme der jeweiligen Region erworben werden würden.

Beiden Versuchspersonen wurde gesagt, dass sie sich innerhalb von 15 min hinsichtlich der Verteilung der 25 Regionen verstän- digt haben sollten. Um bei einem Teil der Versuchspersonen ein Fairnessziel zu etablieren, erhielten sie schriftlich die Information, dass faire Verhandlungsergebnisse häufig nur sehr schwierig zu erreichen sind, und dass sie sich aus diesem Grund, kurz bevor sie in die Verhandlungen eintreten, die folgende Zielintention setzen sollten: »lch will eine faire Lösung finden!«. Die Hälfte der Versuchspersonen mit einem Fairnessziel wurde zusätzlich gebeten, sich außer dieser Zielintention auch noch den Vorsatz »Und wenn ich ein Angebot erhalte, dann werde ich ein faires Gegenangebot machen!« zu fassen. Versuchspersonen der Kontrollbedingung erhielten weder das Fairnessziel noch den Vorsatz. Das Verhandlungsergebnis wurde anhand des individuellen Profits innerhalb jeden Paares von Verhandlungsführern ermittelt. Für jede der drei Bedingungen wurde geprüft, inwieweit die Differenz des Profits innerhalb eines Verhandlungspaares sich signifikant von Null unterschied.

In der Zielintentions- und in der Kontrollbedingung konnten in Abhängigkeit vom Framing signifikante Unterschiede im Profit beobachtet werden: Die Versuchspersonen, die einem Verlustframing unterzogen worden waren, erzielten höhere Profite als die Versuchspersonen, die einem Gewinnframing unterzogen worden waren. Erfreulicherweise wurden solch unfaire Ergebnisse in der Vorsatzbedingung nicht mehr beobachtet - in dieser Bedingung waren die Profite zwischen den Versuchspersonen gleich verteilt.
Alle Versuchspersonen fassten sich vor Beginn des Experiments die Zielintention »Ich will so viele Benutzungsmöglichkeiten wie möglich nennen!«. Eine Hälfte der Versuchspersonen ergänzte diese Zielintention mit dem Vorsatz »Und wenn ich eine bestimmte Nutzungsmöglichkeit gefunden habe, dann werde ich sofort dazu übergehen, eine weitere Nutzungsmöglichkeit zu finden!«. Als abhängige Variable wurde die Anzahl der Benutzungsmöglichkeiten erhoben, die innerhalb von 12 min generiert worden waren. Versuchspersonen der Zielintentionsbedingung nannten in der Bedingung »kollektive Leistungsrückmeldung « deutlich weniger Benutzungsmöglichkeiten als in der Bedingung »individuelle Leistungsrückmeldung«. Dieser Social-loafing-Effekt konnte in der Vorsatzbedingung nicht mehr beobachtet werden - hier wurden unabhängig von der Rückmeldungsbedingung gleich viele Benutzungsmöglichkeiten des Messers genannt.

\section{Vorsatzbildung und konkurrierende Ziele}

Die Theorie des automatischen Zielstrebens (Bargh, 1990; Bargh \& Gollwitzer, 1994) nimmt an, dass jedes bewusste Zielstreben, das häufig und konsistent in einer bestimmten Situation gezeigt wird, von dieser kritischen Situation irgendwann direkt und ohne bewusste Absicht ausgelöst wird (Bargh, 1990; Bargh \& Gollwitzer, 1994). Wenn eine Zielintention auf diese Weise aktiviert werden kann, nennt man sie ein »chronisches Ziel«. Um zu untersuchen, ob Vorsätze das aktuelle Zielstreben vor direkt aktivierten, chronischen Zielen schützen können, wurden zwei Experimente durchgeführt (Gollwitzer, 1998).

In der 1. Studie wurde ein Fahrsimulator benutzt, mithilfe dessen Versuchspersonen ein Auto über eine Rennstrecke fahren mussten. Während zwei Baseline-Messungen wurden die durchschnittliche Fahrgeschwindigkeit und Fahrfehler der Versuchspersonen gemessen. Im Anschluss erhielten sie genaue Instruktionen, wie sie die nächsten beiden Runden fahren sollten.

- Versuchspersonen der Zielintentionsbedingung wurden gebeten, sich das Ziel zu setzen, den Zielpfosten so schnell wie möglich ohne Fehler zu erreichen.

- Versuchspersonen der Vorsatzbedingung sollten sich zusätzlich die Vorsätze fassen: »Und wenn ich in eine Kurve einfahre, dann reduziere ich die Geschwindigkeit! Sobald ich wieder eine gerade Strecke erreiche, dann beschleunige ich wieder!«

Bevor den Versuchspersonen erlaubt wurde, die letzten beiden Runden auf der Autorennbahn zu fahren, wurden die folgenden beiden Zielsetzungen außerhalb des Bewusstseins der Versuchspersonen aktiviert (was als »Priming « von Zielen bezeichnet wird): Die Versuchspersonen mussten auf verschiedenen Blättern präsentierte nummerierte Punktesets so schnell wie möglich miteinander verbinden, was in unterschiedlichen Figuren (Blumen, Tiere und anderen Objekten) resultierte. In der Priming-Bedingung "schnell sein « wurde den Versuchspersonen aufgetragen, innerhalb von 5 min so viele Figuren wie möglich zu generieren. In der Priming-Bedingung »langsam sein « mussten die Punkte so sorgfältig wie möglich verbunden werden, so dass schöne Bilder entstehen. Es zeigte sich in den letzten beiden Runden, dass das Priming »schnell sein« vs. »langsam sein« sehr starke Effekte auf das Fahrverhalten von Versuchspersonen in der Zielintentionsbedingung hatte: Wurde bei den Versuchspersonen das Ziel 
- Tabelle 12.3. Effekte von Vorsätzen

\section{Effekte von Vorsätzen}

Kontrolle unerwünschten Verhaltens

Vorsätze, welche das unerwünschte Denken, Fühlen und Handeln unterdrücken ("Suppressionsvorsätze«)

Hemmung automatischer Aktivierung von Stereotypen (z. B. Altersstereotyp, Frauenstereotyp)

Hemmung vorurteilsbehafteter Reaktionen (z. B. Benachteiligung von Frauen in Männerberufen wird aufgehoben)

Ablenkung während komplexer Aufgaben wird kontrolliert (z. B. Ablenkung durch Werbefilme während mathematischer Aufgaben)

Kontrolle impulsiven Verhaltens bei Kindern mit ADHS (z. B. Stoppreaktion während einer Reaktionszeitaufgabe wird gefördert)

Vorsätze, welche unerwünschtes Verhaltens durch antagonistisches Verhalten ersetzen

Hemmung automatischer Aktivierung von Vorurteilen (z. B. Vorurteile gegenüber Obdachlosen)

Kontrolle negativer Emotionen (z. B. Ekel)

Gesundheitsschädliches Verhalten wird kontrolliert (z. B. Zigaretten- und Alkoholkonsum)

Vorsätze, welche die erwünschte Handlung von unerwünschten internen und externen Einflüssen abschirmen

Nachteilige Kontexteinflüsse werden ausgeblendet (z. B. Deindividuierung, konkurrierende Zielaktivierungen, Framingeffekte)

Nachteilige Selbstzustände werden blockiert (z. B. symbolische Unvollkommenheit, Stimmung, verminderte Selbstregulierungskapazität)
Fördern erwünschten Verhaltens

Vorsätze, welche die Initiierung und Durchführung zielförderlicher Handlungen unterstützen

Argumente gegen rassistische Äußerungen werden schneller genannt

Erhöhung der Wahrscheinlichkeit an Krebsvorsorgeuntersuchungen teilzunehmen (z. B. Mammografie)

Verarbeitung stereotypinkonsistenter Informationen trotz kognitiver Belastung (z. B. bei kognitiver Belastung der zentralen Exekutive)

Vorsätze, welche die Persistenz zielförderlicher Handlungen unterstützen

Regelmäßig Einnahme von Vitamintabletten und lebensnotwendigen Medikamenten wird unterstützt

Unterstützung schwieriger Patientengruppen bei der Durchführung von schwierigen Alltagshandlungen (z. B. Drogenabhängige, die einen Lebenslauf verfassen sollen)

Durchführung sportlicher Übungen im Rehabilitationsbereich wird gefördert (z. B. nach Hüftgelenksoperationen) "schnell sein« aktiviert, fuhren sie schneller und machten mehr Fehler als bei Aktivierung des Ziels »langsam sein«. Versuchspersonen in der Vorsatzbedingung zeigten dagegen diesen Effekt der Zielaktivierung nicht, sondern unabhängig von der Art des Primings eine mittlere Fahrgeschwindigkeit; hierbei machten sie auch kaum Fehler. Dieser Befund weißt darauf hin, dass immer, wenn das Streben nach einem Ziel durch einen Vorsatz sorgfältig geplant wird, konkurrierende nichtbewusste (situativ aktivierte) Ziele keinen Einfluss mehr auf das Handeln der Person haben.

Die bisher gefundenen Effekte von Vorsätzen sind in 0 Tabelle 12.3 zusammengefasst.

\subsection{Potenzielle Kosten der Handlungs- kontrolle durch Vorsätze}

Wie bisher dargestellt wurde, erleichtert das Fassen von Vorsätzen auf vielfältige Art und Weise das Realisieren von Zielen. In Anbetracht der Tatsache, dass Vorsätze ein sehr effektives Mittel der Selbstregulation darstellen, stellt sich die Frage, ob sie auch mit unvorhergesehenen Kosten verknüpft sind. An dieser Stelle werden deshalb die potenziellen Kosten von Vorsätzen angesprochen:

1. Die Möglichkeit der Verursachung einer gewissen Verhaltensrigidität, die sich bei Aufgaben, die hohe Flexibilität erfordern, sehr ungünstig auswirken könnte.

2. Eine starke Verminderung der Selbstregulierungskapazität verursacht durch vorsatzgeleitetes Zielstreben, die zu Defiziten in nachfolgenden Selbstregulationsaufgaben führen sollte.

3. Das Auftauchen von so genannten Rebound-Effekten in dem Sinne, dass nach einer erfolgreichen Unterdrückung unerwünschter Gedanken, Gefühle und Handlungen durch einen Vorsatz innerhalb eines bestimmten Kontextes genau diese Gedanken, Gefühle und Handlungen in einem anderen Kontext möglicherweise wieder, und dann sogar verstärkt, auftauchen.

\subsubsection{Rigidität und vorsatzgesteuertes Handeln}

Hinsichtlich der Rigidität von Vorsätzen stellt sich die Frage, inwiefern ein Handelnder, der sich einen Vorsatz gefasst hat, in der 
Lage ist, günstige Gelegenheiten zu nutzen, die nicht im Vorsatz spezifiziert wurden, die sich aber trotzdem sehr gut zur Realisierung der Zielintention eignen würden. Nimmt man an, dass durch das Fassen eines Vorsatzes strategisch automatische Prozesse ausgelöst werden, die ihrerseits kognitive Ressourcen freisetzen, die nun zur Verarbeitung anderer Reize etc. genutzt werden können, so sollte es möglich sein, Informationen über neu auftauchende Situationen so zu verarbeiten, dass das im Vorsatz definierte zielfördernde Verhalten nun bei diesen neuen Gelegenheiten anstatt der im Vorsatz definierten ursprünglichen Situation gezeigt werden kann. Diese Annahme bestätigte sich in einer Reihe von Studien, bei denen das Fassen eines Vorsatzes letztlich nicht darin resultierte, dass sich Versuchspersonen von einem sich verändernden Kontext oder von einer unerwartet auftauchenden günstigen Situation zur Zielrealisierung nicht beeinflussen ließen. Vielmehr wurde angemessen auf die neue Situation reagiert, anstatt rigide an der vorgenommenen Gelegenheit festgehalten.

So konnte Achtziger (2003, Studie 2) zeigen, dass Versuchspersonen die Gültigkeit ihrer Vorsätze an die Anwesenheit bestimmter kontextueller Hinweisreize binden können. Versuchspersonen konnten in einer Studie zur Kontrolle der Vorurteilsaktivierung gegenüber Fußballfans den Vorsatz »Wenn ich einen Fußballfan sehe, dann bin ich vorurteilsfrei!« in Abhängigkeit vom aktuellen Kontext und somit flexibel realisieren. In dieser Studie galt das Erklingen eines bestimmten Tons als Signal dafür, dass der Vorsatz realisiert werden sollte, während bei Ausbleiben des Tons der Vorsatz nicht realisiert werden musste. Gemäß der Annahme, dass Vorsätze nicht unbedingt zu einer Rigidität des Verhaltens führen müssen, zeigten die Ergebnisse eine gelungene Inhibition von Vorurteilen gegenüber »Fußballfans « angesichts von Bildern, die Fußballfans darstellten, wenn diese Bilder von einem Tonsignal begleitet wurden, jedoch nicht bei dessen Ausbleiben. Genauso konnte gezeigt werden, dass das unerwartete Auftauchen einer günstigen Gelegenheit zur Realisierung der Zielintention, welche nicht im Vorsatz als »Bedingung « definiert worden war, dazu führte, dass die Versuchspersonen nun diese neue Gelegenheit nutzten, um ihr Ziel zu erreichen und nicht die ursprünglich im Vorsatz spezifizierte. Teilnehmer dieser Studie sollten von zwei auf einem Bildschirm präsentierten Symbolen (z. B. Blume, Herz) dasjenige Symbol auswählen, das ihnen die höchste Punktzahl einbrachte. Die Punktzahl jedes Symbols wurde ihnen vor der Studie genannt. Ein Teil der Versuchspersonen hatte sich den Vorsatz gefasst, bei Erscheinen des Symbols mit der absolut höchsten Punktzahl dieses ganz besonders schnell per Tastendruck auszuwählen. Als nach einer Weile ein neues Symbol mit einer noch höheren Punktezahl auf dem Bildschirm präsentiert wurde, schafften es auch Versuchspersonen der Vorsatzbedingung, dieses Symbol anstatt des früheren, mit der höchsten Punktezahl ausgestatteten Symbols, auszuwählen (vgl. Gollwitzer, Parks-Stamm, Jaudas \& Sheeran, 2009).

\subsubsection{Vorsätze und Selbstregulierungskapazität}

Die Annahme, dass Vorsätze die Kontrolle über zielgerichtetes Verhalten automatisieren, impliziert, dass die Verhaltenskontrolle anhand von Vorsätzen effizient und somit relativ anstrengungsfrei abläuft. Eine Konsequenz hieraus ist, dass die Selbst- regulationskapazität kaum reduziert werden sollte, wenn die Leistung in einer bestimmten Selbstregulationsaufgabe durch Vorsätze reguliert wird. Diese Überlegung wurde durch die bereits in Abschn. 12.5.2 berichteten Studien von Bayer et al. (2010) und Webb und Sheeran (2003) unterstützt. Weder bei einer verminderten Selbstregulierungskapazität aufgrund der vorsatzgesteuerten Kontrolle starker Emotionen (Bayer et al., 2010) noch aufgrund der vorsatzgesteuerten Kontrolle von anstrengenden Aufgaben (Durchführung der Stroop-Aufgabe; Webb und Sheeran, 2003) wurde die Selbstregulierungskapazität vermindert.

\subsubsection{Vorsätze und Rebound-Effekte}

Wegner (1994) berichtet, dass Personen, die sich ein bestimmtes mentales Kontroll- oder Suppressionsziel setzen, wie z. B. »Ich will nicht an rosa Elefanten denken! «, dieses Ziel zunächst zwar erreichen, direkt danach aber die durch dieses Ziel unterdrückten Gedanken häufiger haben als Personen, die sich kein solches Suppressionsziel gesetzt hatten. Teilnehmer seiner Studien setzten sich derartige Ziele und sollten immer dann eine Glocke läuten, wenn sie trotz ihrer Zielsetzung an einen rosa Elefanten gedacht hatten. Versuchspersonen mit dem Ziel, nicht an rosa Elefanten zu denken, waren in der Lage, dieses Ziel zunächst einmal zu realisieren. In einer anschließenden 2. Phase, in der alle Versuchspersonen frei vor sich hin assoziieren und dabei all ihre Gedanken niederschreiben sollten, stellte sich jedoch heraus, dass diejenigen Personen, welche sich zu Beginn des Experiments das Ziel gefasst hatten, nicht an rosa Elefanten zu denken, nun wesentlich häufiger Gedanken hatten, die sich auf rosa Elefanten bezogen, als Versuchspersonen, die sich kein derartiges Suppressionsziel gesetzt hatten. Dieser Effekt wird als Rebound-Effekt bezeichnet:

\section{( Definition}

Beim Rebound-Effekt kommen nach dem »Erlöschen« eines Ziels, das mit der Unterdrückung bestimmter Gedanken zu tun hat, diese wieder verstärkt zum Tragen.

Es stellt sich aufgrund solcher Forschungsergebnisse in der Vorsatzforschung die Frage, ob das Fassen von Suppressionsvorsätzen zwar zunächst zu einer erfolgreichen Unterdrückung unerwünschter Gedanken und Gefühle führt, dass aber möglicherweise in einem neuen Kontext Rebound-Effekte hinsichtlich der vorher durch den Vorsatz unterdrückten Gedanken bzw. Gefühle auftauchen. Gollwitzer et al. (2004) führten zur Überprüfung dieser Frage zwei Studien durch. Die Versuchspersonen dieser Studien sollten zunächst in einer Eindrucksbildungsaufgabe hinsichtlich einer bestimmten, genau beschriebenen obdachlosen Person jedwede stereotypen Urteile unterdrücken. In einer nachfolgenden Aufgabe wurde dann entweder anhand eines Fragebogens die Bewertung von Obdachlosen generell erfasst (Gollwitzer et al., 2004, Studie 1) oder mithilfe einer lexikalischen Entscheidungsaufgabe die kognitive Zugänglichkeit von stereotypen Inhalten bezüglich Obdachloser erhoben (Gollwitzer et al., 2004, Studie 2). Wie erwartet zeigten in beiden Studien diejenigen Versuchspersonen, die sich während der Eindrucksbildung nur das Ziel gesetzt hatten, sich keinen stereotypen Eindruck von dem Obdachlosen zu bilden, einen deutlichen Rebound-Effekt: Eine 
ausgeprägte stereotype Beurteilung dieser sozialen Gruppe (Studie 1) und eine höhere Zugänglichkeit stereotyper Inhalte (Studie 2). Versuchspersonen, die diese Zielintention durch einen passenden Suppressionsvorsatz ergänzt hatten, zeigten diesen jedoch nicht.

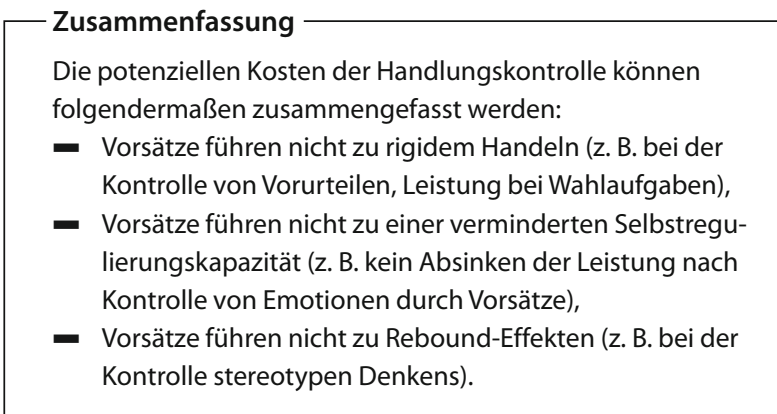

\subsection{Diskussion und Ausblick}

\subsubsection{Fassen von Vorsätzen als narrensichere Selbstregulationsstrategie?}

Auch wenn Vorsätze ihre Wirkung offensichtlich ohne bedeutsame Kosten in Form von Verhaltensrigidität, Rebound-Effekten und verminderter Selbstregulierungskapazität entfalten können, gibt es natürlich trotzdem Situationen, in denen ein Vorsatz nicht zu dem erwünschten Ergebnis führt. So kann es durchaus vorkommen, dass ein Handelnder im »Dann-Teil« seines Vorsatzes ein Verhalten spezifiziert, das außerhalb seiner Kontrolle liegt. Das ist dann der Fall, wenn eine Person, die sich gesund ernähren möchte, zwar plant, dass sie im Restaurant vegetarisches Essen bestellen wird, dann aber ein Restaurant aufsucht, in dem kein solches Essen angeboten wird. Ein weiterer Grund für einen verfehlten Umgang mit Vorsätzen wäre die Definition von Situationen im »Wenn-Teil« des Vorsatzes, die nur sehr selten oder gar nicht eintreten. Wenn beispielsweise eine Person, die beabsichtigt, sich im Restaurant vegetarisches Essen zu bestellen, nur in Ausnahmefällen ein gediegenes Restaurant besucht, sich sonst aber mit Selbstbedienungsrestaurants zufrieden gibt oder gleich zu Hause isst. Ähnliches gilt für die Auswahl von Verhaltensweisen im »Dann-Teil« des Vorsatzes, die für das Erreichen der jeweiligen Absicht in keiner Weise geeignet sind. Das Bestellen vegetarischen Essens in einem Restaurant, in dem vegetarisches Essen grundsätzlich mit sehr fetthaltigem Käse schmackhaft gemacht wird, wäre ein solches Beispiel.

\subsubsection{Prospektives Gedächtnis und neuronale Substrate}

Nachdem in den letzten 24 Jahren v. a. motivationale und volitionale Prozesse von Vorsätzen auf der Urteils- und Verhaltensebene untersucht wurden, sollen in den kommenden Jahren stärker ihre kognitionspsychologischen und neurowissenschaftlichen Aspekte untersucht werden. Im Bereich der Kognitionspsychologie könnte sich für die Vorsatzforschung die prospektive Gedächtnisforschung (vgl. Smith, 2003) als besonders fruchtbares Feld erweisen, da sie Prozesse des Speicherns und Abrufens von Intentionen aus dem Langzeitgedächtnis untersucht. In einer MEG-Studie konnten für verschiedene Zielsetzungsstrategien (mentales Kontrastieren vs. Schwelgen in positiven Zukunftsfantasien; vgl. Oettingen, Pak \& Schnetter, 2001) durch MEG-Messungen deren Assoziation mit unterschiedlichen Hirnarealen identifiziert werden (Achtziger, Fehr, Oettingen, Gollwitzer \& Rockstroh, 2009). Insgesamt ließ sich in dieser Studie eine erhöhte Gehirnaktivierung während des mentalen Kontrastierens im Vergleich zum Schwelgen in positiven Zukunftsfantasien beobachten. In einer anderen Studie wurde herausgefunden, dass die Kontrolle negativer Emotionen (z. B. Ekel) mithilfe von Vorsätzen mit anderen elektrokortikalen Reaktionen einhergeht als die Kontrolle negativer Emotionen mittels bloßer Zielintentionen (Schweiger Gallo, Keil, McCulloch, Rockstroh \& Gollwitzer, 2009). Handlungskontrolle durch Vorsätze impliziert dass die notwendigen selbstregulatorischen Prozesse weniger durch die dazu gehörigen übergeordneten Zielintentionen und somit »top-down" gesteuert werden, sondern eher durch Prozesse, die auf »unteren « Verarbeitungsebenen ablaufen (z. B. aufgrund des Auftauchens bestimmter Situationen und somit auch durch Reizkontrolle, d. h. »bottom-up«). Aus diesem Grund wurde vermutet, dass Handlungskontrolle durch Vorsätze mit der Aktivität in der lateralen Area 10 einhergeht, während Handlungskontrollprozesse, denen nur eine Zielintention und nicht zusätzlich ein Wenn-dann-Plan zugrunde lag, stärker mit Aktivität in der medialen Area 10 assoziiert sein sollte. Diese Hypothese konnte in einer fMRI-Studie bestätigt werden (Gilbert, Gollwitzer, Cohen, Oettingen \& Burgess, 2008). Harmon-Jones et al. (2008) zeigten in einer EEG-Studie, dass die aktionale Bewusstseinslage induziert auf Basis des Rubikon-Modells der Handlungsphasen mit hoher links-frontaler Gehirnaktivität assoziiert ist. Generell gilt jedoch festzuhalten, dass es bezüglich der hirnphysiologischen Basis der Handlungskontrolle mittels Zielintentionen vs. Vorsätzen sowie hinsichtlich intentionaler $\mathrm{Zu}$ stände wie beispielsweise der planenden und der aktionalen Bewusstseinslagen noch viel zu entdecken gibt.

\section{Zusammenfassung}

Die Betrachtung der Motivation im Handlungsverlauf erlaubt es zwischen Phänomenen der Zielsetzung (Motivation) und Zielrealisierung (Volition) zu unterscheiden. Während bislang die Analyse der dabei auftretenden kognitiven Orientierung im Vordergrund stand (Bewusstseinslagenforschung), wird es in Zukunft darum gehen, herauszufinden, welche effektiven Selbstregulationsstrategien es einer Person erleichtern, die verschie$\boldsymbol{\nabla}$ denen Aufgaben im Handlungsverlauf effektiv zu lösen. Ein Schritt in diese Richtung ist die Theorie der intentionalen Handlungssteuerung (Gollwitzer, 1993, 1999), die Vorsätze als effektive Strategie für das Lösen von Aufgaben identifiziert, die mit der Initiierung und dem Abschirmen von Zielhandlungen, dem rechtzeitigen Ablösen vom Zielstreben sowie dem Vermeiden einer Überforderung der Handlungskontrollkapazität beim Zielstreben zu tun haben. 
Zukünftige Forschung sollte versuchen, einerseits weitere effektive Selbstregulationsstrategien für die Lösung der genannten Probleme zu identifizieren; andererseits sollte die Suche nach effektiven Selbstregulationsstrategien auch auf weitere Handlungsphasen ausgeweitet werden. Für die prädezisionale Handlungsphase des Zielsetzens ist dies bereits geschehen. Die Theorie der Fantasierealisierung (Oettingen, $1996,2000)$ spezifiziert verschiedene Strategien des Zielsetzens (mentale Kontrastierung von erwünschter Zukunft und augenblicklicher Gegenwart, Schwelgen in der positiven Zukunft, Grübeln über die momentane negative Gegenwart), wobei nur die mentale Kontrastierung garantiert, dass Ziele im Einklang mit den wahrgenommenen Erfolgserwartungen gesetzt werden. Das heißt, dass weder überfordernde noch unterfordernde Ziele verfolgt werden, sondern solche, die das Handlungspotenzial der Person maximal ausschöpfen. Zukünftige Forschung zu effektiven Selbstregulationsstrategien sollte jedoch nicht nur die Handlungsphase des Zielsetzens beleuchten, sondern auch die Handlungsphase der Bewertung eines abgeschlossenen Zielstrebens. Auch hier dürften sich Selbstregulationsstrategien unterscheiden lassen, die für erfolgreiches nachfolgendes Zielstreben der Person mehr oder weniger förderlich sind. Das letztendliche Ziel dieser Forschung ist, Interventionsprogramme zu entwickeln, die darauf abzielen, Personen Handlungskontrollstrategien zu vermitteln, die es innen erlauben, die Probleme des Zielstrebens so wie sie in den verschiedenen Handlungsphasen auftreten, erfolgreicher zu lösen.

\section{? Zur Wiederholung}

- Die Antworten auf die folgenden Fragen finden Sie unter www.lehrbuch-psychologie.de (Motivation und Handeln), im Lerncenter zu diesem Kapitel.

1. Welche vier Phasen unterscheidet das Rubikon-Modell der Handlungsphasen?

2. Am Ende welcher Phase des Rubikon-Modells wird eine verbindliche Intention gebildet und somit »der Rubikon« überschritten?

3. Welche Effekte auf die Selbsteinschätzung werden durch die abwägende bzw. die planende Bewusstseinslage generiert?

4. Wie wird die planende Bewusstseinslage, wie die abwägende Bewusstseinslage experimentell manipuliert?

5. Welche Effekte hat die abwägende Bewusstseinslage, welche Effekte die planende Bewusstseinslage auf die Informationsverarbeitung?

6. Nach Induktion welcher Bewusstseinslage werden Ziele eher realisiert?

7. Welche Auswirkungen hat eine abwägende Bewusstseinslage auf die Einschätzung von Partnerschaften?

8. Wie wird eine »Zielintention « definiert?

9. Wie wird ein $»$ Vorsatz« definiert?

10. Was will man mit Vorsätzen erreichen?

11. Welche Moderatorvariablen gibt es hinsichtlich der Wirkung von Vorsätzen?

12. Erfordert die Realisierung von Vorsätzen kognitive Ressourcen?

13. Welche positiven Effekte können Vorsätze im Gesundheitsbereich haben?

14. Wie können unerwünschte Effekte wie Stereotypisierung anderer Personen durch Vorsätze verhindert werden? 